\title{
Vpx rescues HIV-1 transduction of dendritic cells from the antiviral state established by type 1 interferon
}

Thomas Pertel, Christian Reinhard and Jeremy Luban ${ }^{*}$

\begin{abstract}
Background: $V p x$ is a virion-associated protein encoded by SIV $V_{S M}$, a lentivirus endemic to the West African sooty mangabey (Cercocebus atys). HIV-2 and SIV $\mathrm{MAC}_{\text {, zoonoses resulting from SIV }}$ SM transmission to humans or Asian rhesus macaques (Macaca mulatta), also encode Vpx. In myeloid cells, Vpx promotes reverse transcription and transduction by these viruses. This activity correlates with Vpx binding to DCAF1 (VPRBP) and association with the DDB1/RBX1/CUL4A E3 ubiquitin ligase complex. When delivered experimentally to myeloid cells using VSV Gpseudotyped virus-like particles (VLPS), Vpx promotes reverse transcription of retroviruses that do not normally encode Vpx.
\end{abstract}

Results: Here we show that Vpx has the extraordinary ability to completely rescue HIV-1 transduction of human monocyte-derived dendritic cells (MDDCs) from the potent antiviral state established by prior treatment with exogenous type 1 interferon (IFN). The magnitude of rescue was up to 1,000-fold, depending on the blood donor, and was also observed after induction of endogenous IFN and IFN-stimulated genes (ISGs) by LPS, poly(I:C), or poly $(\mathrm{dA}: \mathrm{dT})$. The effect was relatively specific in that Vpx-associated suppression of soluble IFN- $\beta$ production, of mRNA levels for ISGs, or of cell surface markers for MDDC differentiation, was not detected. Vpx did not rescue HIV-2 or SIV $V_{\text {MAC }}$ transduction from the antiviral state, even in the presence of SIV $\mathrm{MAC}$ or HIV-2 VLPs bearing additional Vpx, or in the presence of HIV-1 VLPs bearing all accessory genes. In contrast to the effect of Vpx on transduction of untreated MDDCs, HIV-1 rescue from the antiviral state was not dependent upon Vpx interaction with DCAF1 or on the presence of DCAF1 within the MDDC target cells. Additionally, although Vpx increased the level of HIV-1 reverse transcripts in MDDCs to the same extent whether or not MDDCs were treated with IFN or LPS, Vpx rescued a block specific to the antiviral state that occurred after HIV-1 CDNA penetrated the nucleus.

Conclusion: Vpx provides a tool for the characterization of a potent, new HIV-1 restriction activity, which acts in the nucleus of type 1 IFN-treated dendritic cells.

\section{Background}

In addition to the gag, pol, and env genes common to all retroviruses, lentiviruses including HIV-1 bear specialized genes such as $v p r$ that contribute to viral replication and pathogenesis [1]. Simian immunodeficiency viruses isolated from West African sooty mangabeys $\left(\mathrm{SIV}_{\mathrm{SM}}\right)$ possess $v p r$ as well as a highly homologous gene called $v p x$. The latter may have been generated by $v p r$ gene duplication [2] or by recombination with an SIV that possessed a highly divergent $v p x$ [3]. HIV-2

\footnotetext{
* Correspondence: jeremy.luban@unige.ch

Department of Microbiology and Molecular Medicine, University of Geneva, Geneva, Switzerland
}

and $\mathrm{SIV}_{\mathrm{MAC}}$, zoonoses derived from $\mathrm{SIV}_{\mathrm{SM}}$, also possess both of these genes.

Neither vpr nor $v p x$ is essential for virus replication in tissue culture, but both contribute to virus replication and disease progression in animal models $[4,5]$. The effect of these genes in vivo is possibly linked to their ability to enhance virus replication in dendritic cells and macrophages in tissue culture [6-15]. Myeloid cells are believed to be critical targets for lentiviruses in vivo, partly because they are capable of productive infection, but also because they facilitate virus transmission to CD4 ${ }^{+}$T-cells [16-18].

\section{Biomed Central}


Via interaction with short peptide signals in the carboxy-terminus of the Gag polyprotein, the Vpr and Vpx proteins are incorporated into nascent virions as the particles exit productively infected cells [19-22]. The presence of these proteins within virions suggests that they play a role in the early steps of lentivirus infection, prior to de novo protein synthesis directed by transcripts from the new provirus. Vpr and Vpx promote reverse transcription soon after the virions enter the target cell cytoplasm $[10,13,14]$. Other studies suggested that Vpr and $\mathrm{Vpx}$ are required later in the retrovirus life cycle to promote nuclear import of the preintegration complex [23-26], though the significance of the latter findings have been questioned $[27,28]$.

Attempts to saturate a hypothetical HIV-1-specific restriction factor in monocyte-derived dendritic cells (MDDC) using HIV-1 VLPs have led to the fortuitous discovery that SIV MAC VLPs increase HIV-1 reverse transcription and infectivity in these cells, so long as the VLPs possess Vpx $[10,11,29]$. Similar stimulation of infectivity was observed with proteasome inhibitors, suggesting that Vpx promotes the degradation of an antiviral factor; CUL5-dependent degradation of the antiviral protein APOBEC3G by the lentiviral accessory protein Vif offered compelling precedent for such a model [30-32]. Indeed, heterokaryon experiments suggested that myeloid cells possess a dominant-acting, Vpx-sensitive inhibitor of lentiviral infection [12]. Via direct binding to DCAF1 (also known as VPRBP), both Vpr and Vpx associated with the DDB1/RBX1/CUL4A E3 ubiquitin ligase complex [12,13,15,33-37]. Vpx mutants that do not bind DCAF1 are unable to stimulate infectivity in myeloid cells $[12,13,15]$.

Here, we report the results of experiments designed to determine the effect of Vpx on HIV-1 transduction of MDDCs in the face of the potent antiviral state preestablished by treatment with exogenous type 1 interferon (IFN) or with agonists of pattern recognition receptor (PRRs) that stimulate endogenous type 1 IFN production and the transcription of interferon stimulated genes (ISGs).

\section{Results}

SIV $_{\text {MAC }}$ VLPs rescue HIV-1 infection from type I IFN

The Vpx proteins of SIV $\mathrm{VAC}_{\mathrm{C}}$ and HIV-2 promote transduction of myeloid cells by these viruses [6-15]. Though HIV-1 does not possess a gene encoding Vpx, the infectivity of HIV-1 in myeloid cells is also increased by SIV virus-like particles (VLPs) bearing Vpx [10,11,29]. Interest in potential links between retroviral restriction factors and innate immune signaling $[38,39]$ directed us to explore the effect of Vpx on HIV-1 transduction of myeloid cells after an antiviral state had been established by administration of exogenous type 1 IFN.
Human monocyte-derived dendritic cells (MDDC) were generated by culture of $\mathrm{CD} 14^{+}$peripheral blood cells in GM-CSF and IL-4 for 4 days, as previously described [39]. The status of differentiation and maturation was confirmed by observing the typical morphology and by assessing immunofluorescence for standard cell surface markers, including CD1A, CD209 (DC-SIGN), CD14, CD11C, HLA-DR, CD83, and CD86 (additional file 1, Figure S1A and data not shown). When immature MDDCs were challenged with three-part, HIV-1-GFP reporter virus, pseudotyped with vesicular stomatitis

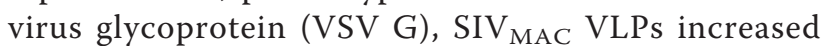
transduction efficiency 3- to 10-fold (Figure 1A, upper panels), depending upon the multiplicity of infection. Challenge of MDDC with HIV-1-GFP 24 h after treatment with exogenous IFN- $\alpha$ resulted in infection levels at or below the detection limit (Figure 1A, lower left panel). In the particular experiment shown in Figure 1, the magnitude inhibition of HIV-1 transduction by IFN$\alpha$ was $\geq 600$-fold. Addition of SIV $_{\text {MAC VLPs to the }}$ MDDCs $24 \mathrm{~h}$ after IFN- $\alpha$ treatment rescued HIV-1 transduction to levels at least as high as those in the absence of IFN- $\alpha$ (Figure 1A, lower right panel). Identical results were obtained when IFN- $\beta$ was substituted for IFN- $\alpha$ (Figure 1B).

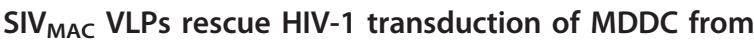 LPS, poly(I:C), or poly(dA:dT)}

Lipopolysaccharide (LPS), the synthetic double-stranded RNA poly(I:C), and the synthetic double-stranded DNA, poly $(\mathrm{dA}: \mathrm{dT})$, each activate IFNB1 transcription and establish a generalized antiviral state [39-42]. Treatment of MDDC with LPS, poly(I:C), or poly(dA:dT) indeed resulted in the production of soluble IFN- $\beta$ (additional file 1, Figure S1B), the synthesis of intracellular MX1 and APOBEC3A proteins (additional file 1, Figure S1C), the transcriptional induction of IFNB1 and other inflammatory genes, including $M X 1, C C L 2, C C L 8, C X C L 10$, IL6, ISG54 (IFIT2), PTGS2, and TNF (additional file 1, Figure S1D), as well as the upregulation of MDDC cell surface maturation markers, including CD86 and CD83 (additional file 1, Figure S1A).

Since LPS, poly $(\mathrm{I}: \mathrm{C})$, and poly $(\mathrm{dA}: \mathrm{dT})$ all elicited type 1 IFN in MDDCs, the ability of each to inhibit HIV-1 transduction was examined. MDDCs were treated for 24 $h$ with either LPS, poly(I:C), or poly $(\mathrm{dA}: \mathrm{dT})$ and then challenged with VSV G-pseudotyped HIV-1-GFP reporter virus. Each of the treatments potently inhibited HIV1-GFP transduction (Figure 2A). When SIV MAC VLPs were added to the culture $24 \mathrm{~h}$ after treatment with any of the PRR agonists, HIV-1-GFP two-part vector transduction was rescued completely (Figure 2A). Similar results were observed when HIV-1 entry was mediated by CCR5-tropic HIV-1 Env, indicating that the effect of 

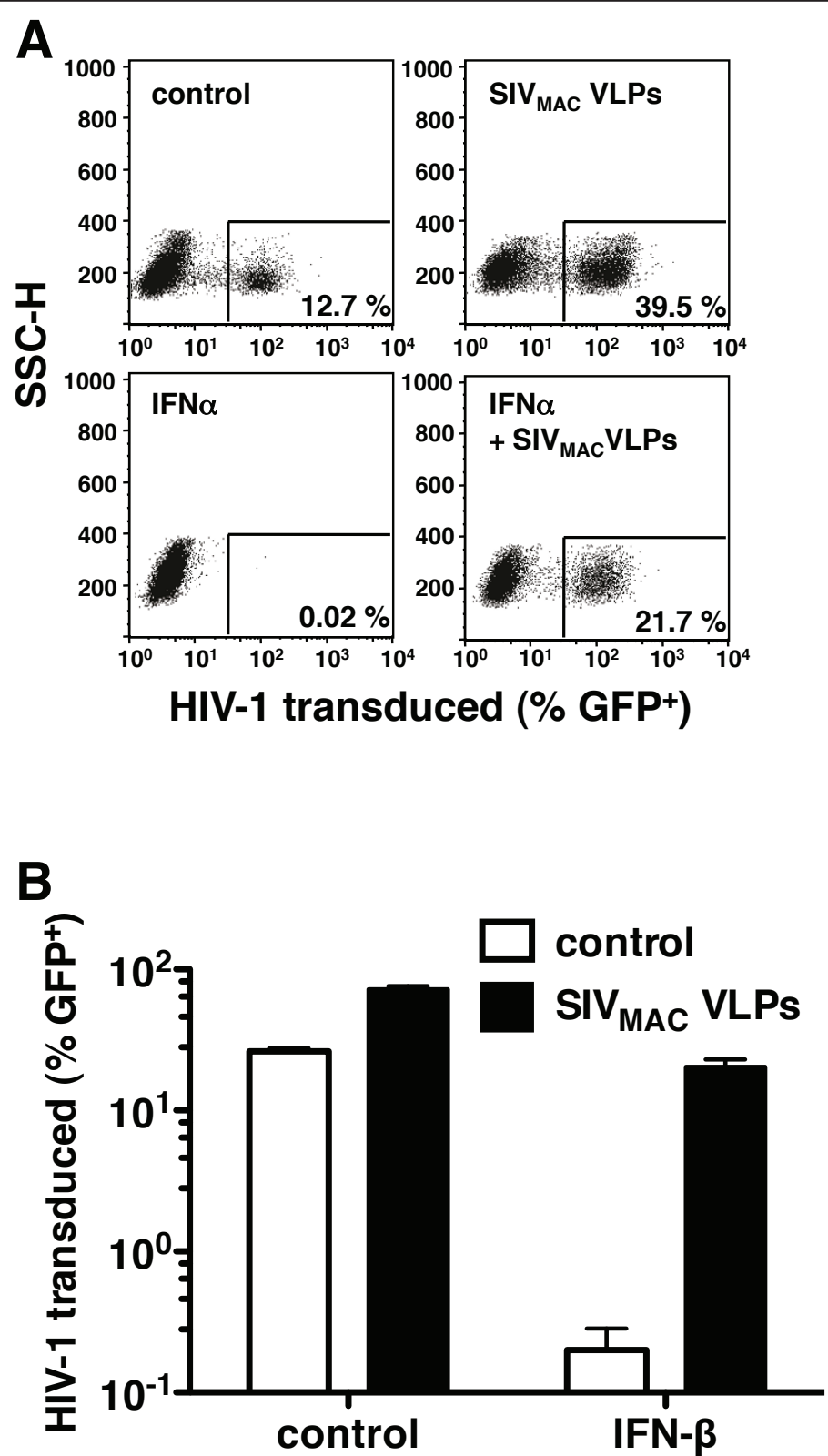

Figure 1 SIV $_{\text {MAC }}$ virus-like particles (VLPs) rescue HIV-1 transduction of human monocyte-derived dendritic cells (MDDCs) from pretreatment with type I ifN. MDDCs were incubated for $24 \mathrm{~h}$ with $10 \mathrm{ng} / \mathrm{mL}$ IFN- $\alpha$ (A) or $10 \mathrm{ng} / \mathrm{mL}$ IFN- $\beta$ (B). The cells were then treated for

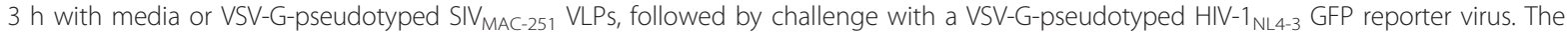
percent GFP-positive cells was determined by flow cytometry $72 \mathrm{~h}$ after transduction. Error bars represent \pm standard deviation $(\mathrm{SD})(n=3)$. In each case, one representative example of at least three independent experiments is shown.

Vpx was not peculiar to VSV G-pseudotyped HIV-1 (Figure 2B). The $\mathrm{SIV}_{\text {MAC }}$ VLPs had no detectable effect on IFN- $\beta$ secretion, MX1 or APOBEC3A protein production, cell-surface levels of MDDC maturation markers, or mRNA induction of IFNB1 and a panel of 8 ISGs (additional file 1, Figure S1). These findings indi-

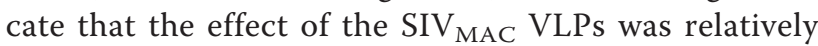
specific and that the VLPs did not globally reverse the antiviral state associated with type 1 IFN.
Vpx is necessary and sufficient to protect HIV-1 from the type I IFN response

Vpx is essential for the boost in HIV-1 transduction of human MDDCs that is provided by SIV $_{\text {MAC VLPs }}$ $[10,11,29]$. To determine if $\mathrm{Vpx}$ is also required for the protective effect of VLPs in the context of the type 1 IFN-associated antiviral state, VLPs bearing Vpx were compared with VLPs lacking Vpx. Either SIV MAC VLPs or HIV-2 VLPs rescued a three-part HIV-1 vector from 


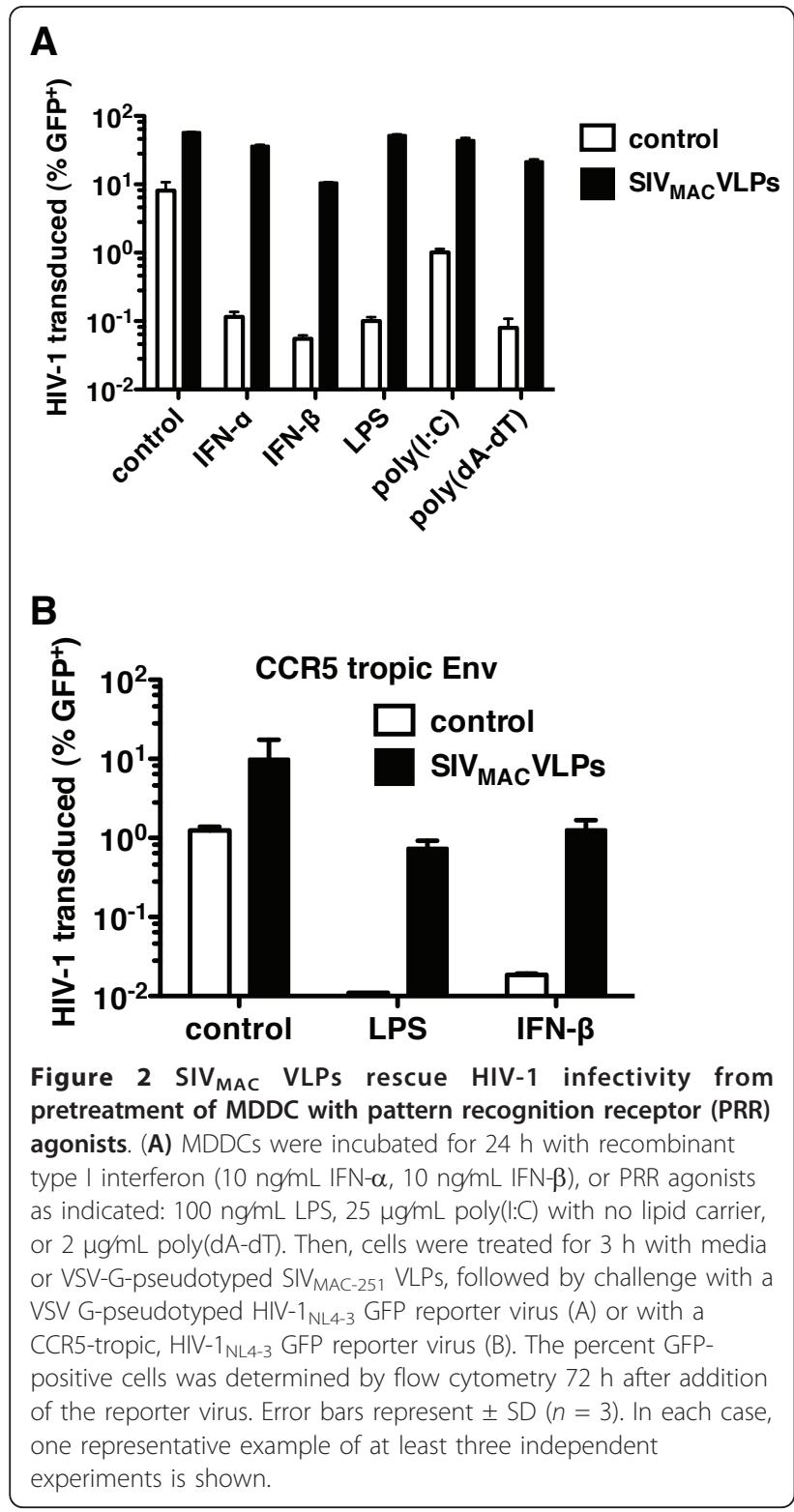

type 1 IFN or LPS treatment in human MDDC, but only when Vpx was present (Figure 3A). The same results were obtained if $v p x$ was provided in cis or in trans with respect to the SIV structural proteins during assembly of the VLPs (additional file 2, Figure S2A), if Vpx was delivered by VLPs or whole SIV virus (additional file 2, Figure S2B), or if Vpx was encoded by HIV-2 ROD, $\operatorname{SIV}_{\text {MAC251 }}$, SIV MAC239, or $\operatorname{SIV}_{\text {SMM-PBJ }}$ (data not shown). Vpr encoded by $\operatorname{SIV}_{\text {MAC }}$, HIV-2, SIV AGM $_{\text {or }}$ HIV-1 did not rescue HIV-1 from the antiviral state and, if anything, decreased the efficiency of rescue by Vpx (additional file 2, Figure S2B).

HIV-1 Gag p6 lacks the carboxy-terminal D-X-A-X-XL-L peptide found in SIV MAC $_{\text {and HIV-2 Gag that }}$

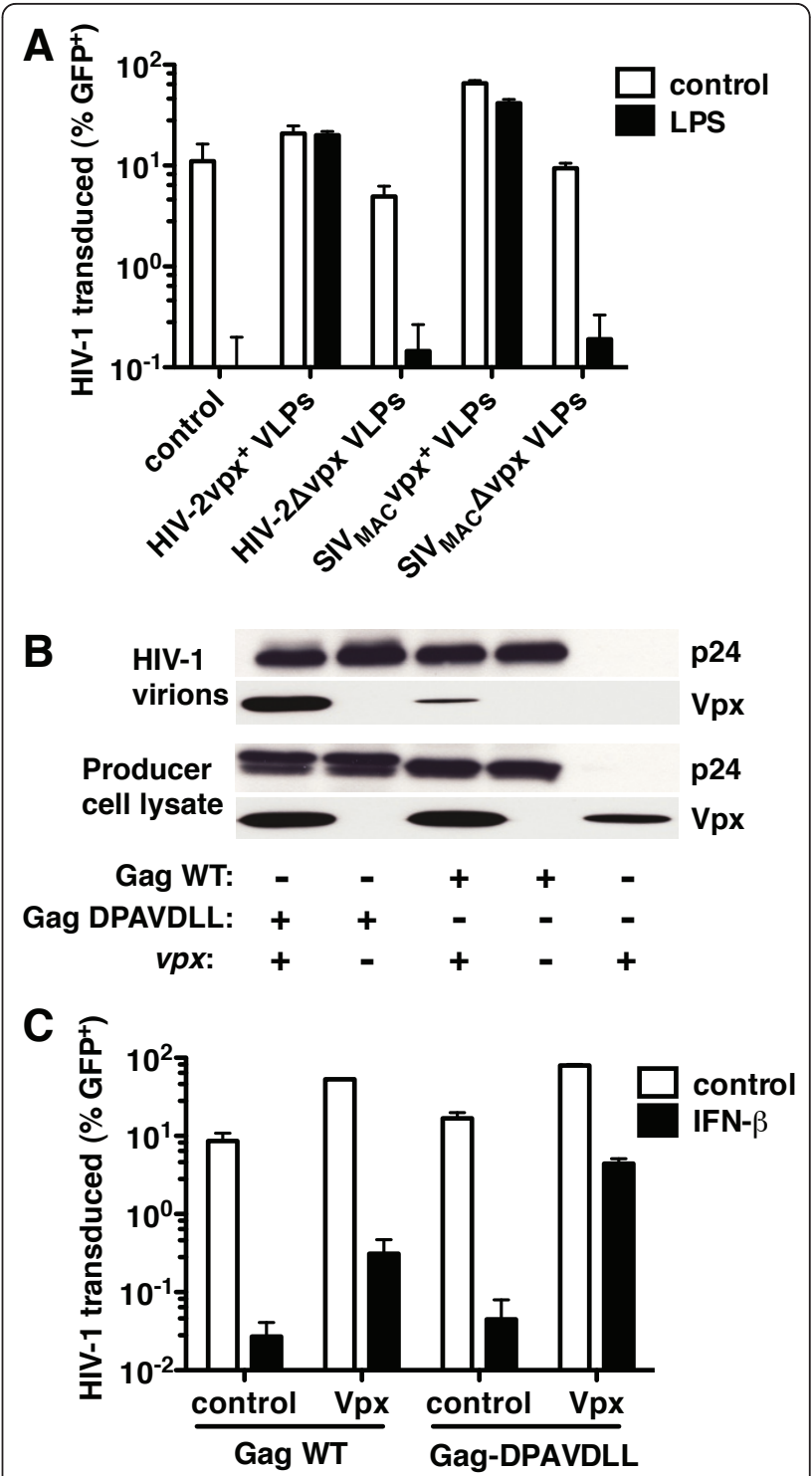

Figure 3 Among VLP constituents, Vpx is necessary and sufficient to rescue HIV-1 from type I IFN. (A) MDDCs were treated with LPS for $24 \mathrm{hrs}$, then treated for 3 hrs with media or the

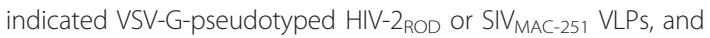
finally challenged with a VSV-G-pseudotyped HIV-1 NL4-3 GFP reporter virus. Infectivity was measured by flow cytometry. (B) As indicated, 293T cells were co-transfected with a codon optimized SIV MAC251 vpx expression plasmid and HIV-1 GFP reporter vectors bearing either wild-type Gag or Gag with an engineered Vpx binding motif (DPAVDLL). Proteins from the cell lysate and from virion preparations were separated by SDS-PAGE and then immunoblotted with anti-Vpx or anti-p24 antibodies. (C) MDDCs treated with IFN- $\beta$ for $24 \mathrm{~h}$ and were then challenged with VSV-G-pseudotyped HIV-1 GFP reporter vectors with wild-type HIV-1 Gag or HIV-1 Gag bearing the engineered Vpx binding motif (DPAVDLL). Both HIV-1 reporter vectors were produced in the presence of empty pcDNA3.1 plasmid or pcDNA3.1 containing a codon-optimized SIV MAC-251 vpx CDNA. Data are representative of one of at least three independent experiments. Error bars represent $\pm S D(n=3)$. 
confers optimal Vpx incorporation into virions $[19-21,43,44]$. Nonetheless, $v p x$ expression in trans during HIV-1 virion production has been reported to result in some Vpx protein incorporation into HIV-1 virions with concomitant increase in the efficiency of MDM transduction by HIV-1 [12]. Vpx protein production directed by a codon-optimized $v p x$ expression plasmid during HIV-1 virion production resulted in detectable Vpx incorporation into HIV-1 virions (Figure 3B) and partial rescue of HIV-1 three-part vector transduction in MDDCs that had been treated 24 hrs previously with IFN- $\beta$ (Figure $3 C$ ). When the Vpx binding motif from the carboxy terminus of SIV $_{\text {MAC }}$ Gag (DPAVDLL) was engineered into HIV-1 Gag, Vpx packaging into HIV-1 virions was more efficient (Figure $3 \mathrm{~B}$ ) and rescue from IFN- $\beta$ by Vpx was 10 -fold more effective than it was with the parent construct (Figure $3 \mathrm{C}$ ). These results

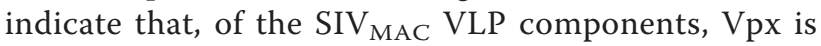
sufficient to rescue HIV-1 transduction from the type 1 IFN-associated antiviral state in MDDCs.

\section{Vpx does not rescue HIV-2 or SIV $_{\text {MAC from the antiviral }}$ state}

As previously described $[6,7,11,45]$, disruption of the $v p x$ open reading frame severely attenuated the transduction of MDDCs by three-part SIV $_{M A C}$ vector (Figure 4A), confirming the importance of $v p x$ for MDDC-transduction in the absence of exogenous type 1 IFN or LPS. In contrast, when an antiviral state was established with exogenous IFN or LPS prior to virus challenge, $v p x$ did not rescue transduction by $\mathrm{SIV}_{\mathrm{MAC}}$ or $\mathrm{HIV}-2$, even when $\mathrm{SIV}_{\text {MAC }}$ or HIV-2 VLPs provided additional Vpx in trans (Figure 4 and additional file 3, Figure S3); in parallel, the same SIV MAC VLPs rescued HIV-1 transduction from the antiviral state in a $v p x$-dependent fashion (Figure 4C). Additionally, HIV-1 VLPs bearing all HIV-1 accessory genes were unable to rescue either

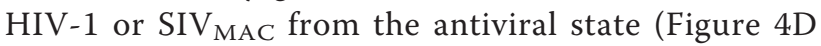
and $4 \mathrm{E})$. These experiments demonstrate that $\mathrm{Vpx}$ has the ability to rescue HIV-1, but not SIV $_{\text {MAC from the }}$ antiviral state.

\section{Rescue of HIV-1 from the antiviral state by Vpx is independent of DCAF1}

Vpx associates with the DDB1/RBX1/CUL4A E3 ubiquitin ligase complex via interaction with DCAF1 $[12,13,15]$. SIV MAC replication in macrophages is compromised by disruption of Vpx association with DCAF1 using $v p x$ mutations Q76A or F80A, or by knockdown of DCAF1 or components of the DDB1/RBX1/CUL4A complex $[12,13,15,35]$. To address the role of DCAF1 and the associated E3 ubiquitin ligase complex in rescue of HIV-1 from the antiviral state in MDDCs, the Q76A and F80A $v p x$ mutations were introduced into a codon-

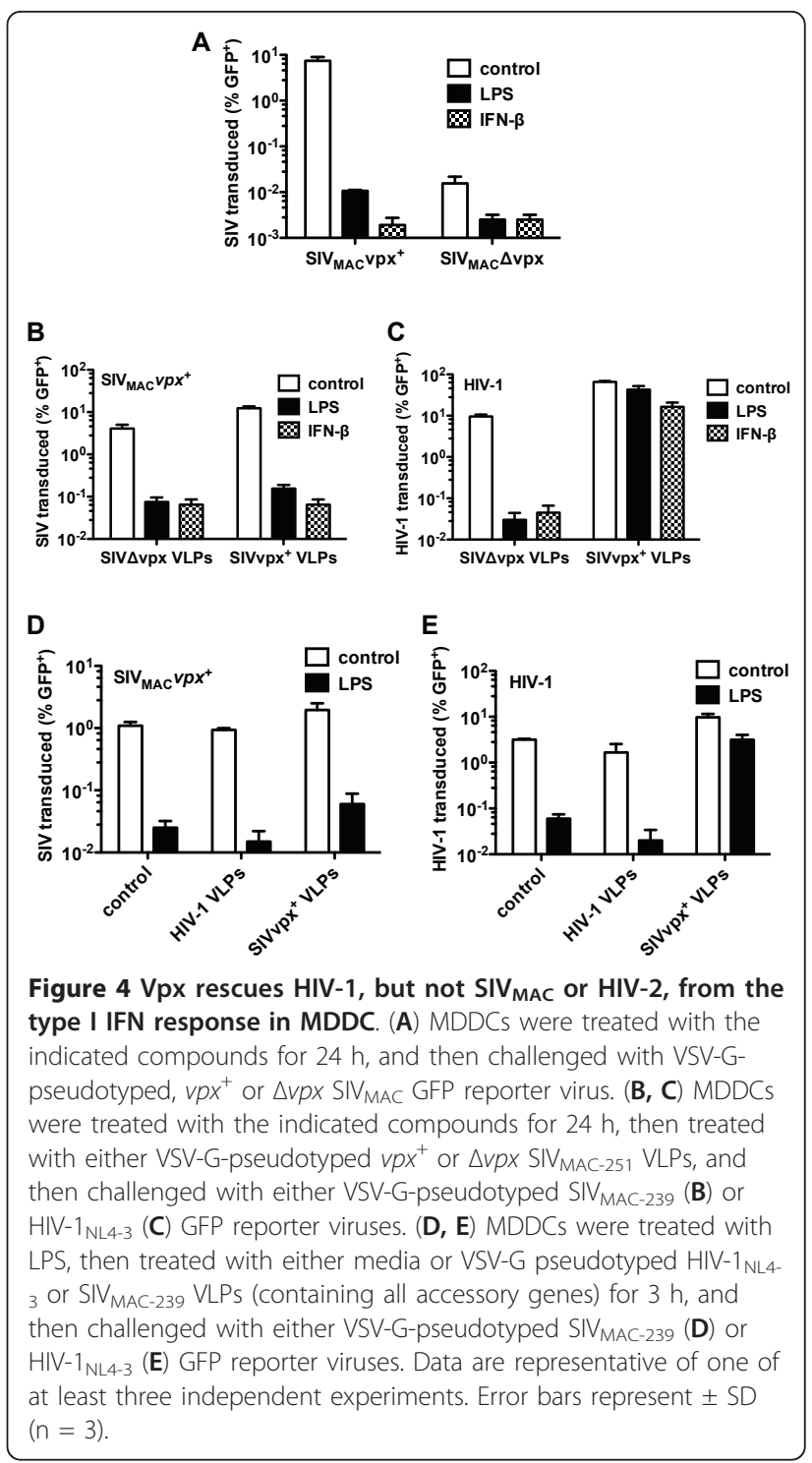

optimized $\mathrm{SIV}_{\text {MAC }} v p x$ expression construct. Both mutant proteins expressed as well as wild type Vpx (Figure $5 \mathrm{~A}$ ) and were efficiently incorporated into SIV $_{\text {MAC }}$ VLPs (Figure 5B). As compared to the wild-type Vpx, the efficiency of HIV-1 rescue from the antiviral state in MDDCs by either mutant was reduced roughly 5-fold (Figure 5C). Nonetheless, both mutants retained the ability to rescue HIV-1 from the antiviral state 140-fold (Figure 5C), indicating that interaction with DCAF1 is not required for this activity.

The importance of DCAF1 for $v p x$-mediated rescue from the antiviral state was examined directly by transducing MDDCs with lentiviral vectors engineered to confer puromycin-resistance and to express RNA polymerase II-driven, microRNA-based short hairpin RNAs targeting either DCAF1 or a control RNA $[39,46]$. Freshly isolated $\mathrm{CD} 14^{+}$monocytes were transduced in 


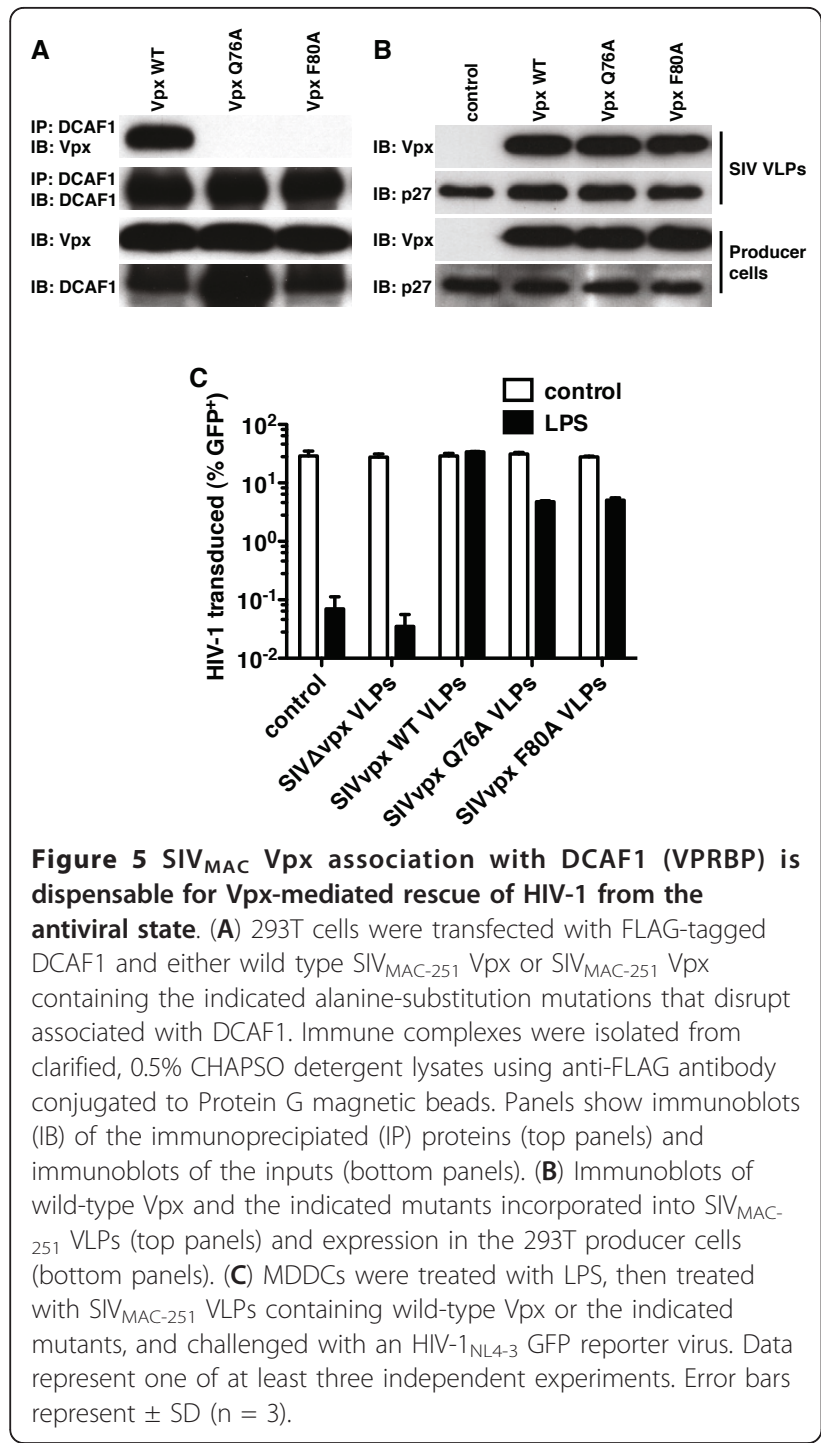

the presence of SIV MAC VLPs to increase the effective titer of the knockdown vectors. Cells were placed in GM-CSF and IL-4, and pools of puromycin-resistant cells were generated with each knockdown vector, as previously described $[39,46]$.

Lysate from MDDCs that had been transduced with knockdown vector targeting DCAF1 was examined by Western blot. In contrast to the strong signal observed with the control knockdown cells, DCAF1 protein was undetectable in the DCAF1-knockdown cells (Figure $6 \mathrm{~A})$, even after cells had been treated with exogenous IFN- $\beta$. The ability of the cells to respond to IFN- $\beta$ was confirmed by showing the induction of $\mathrm{Mx} 1$ protein (Figure 6A). Despite this highly efficient DCAF1 knockdown, little change was observed in the ability of Vpx to rescue HIV-1 transduction from the antiviral state established by IFN- $\beta$ or by LPS (Figure $6 \mathrm{~B}$ and $6 \mathrm{C}$ ).

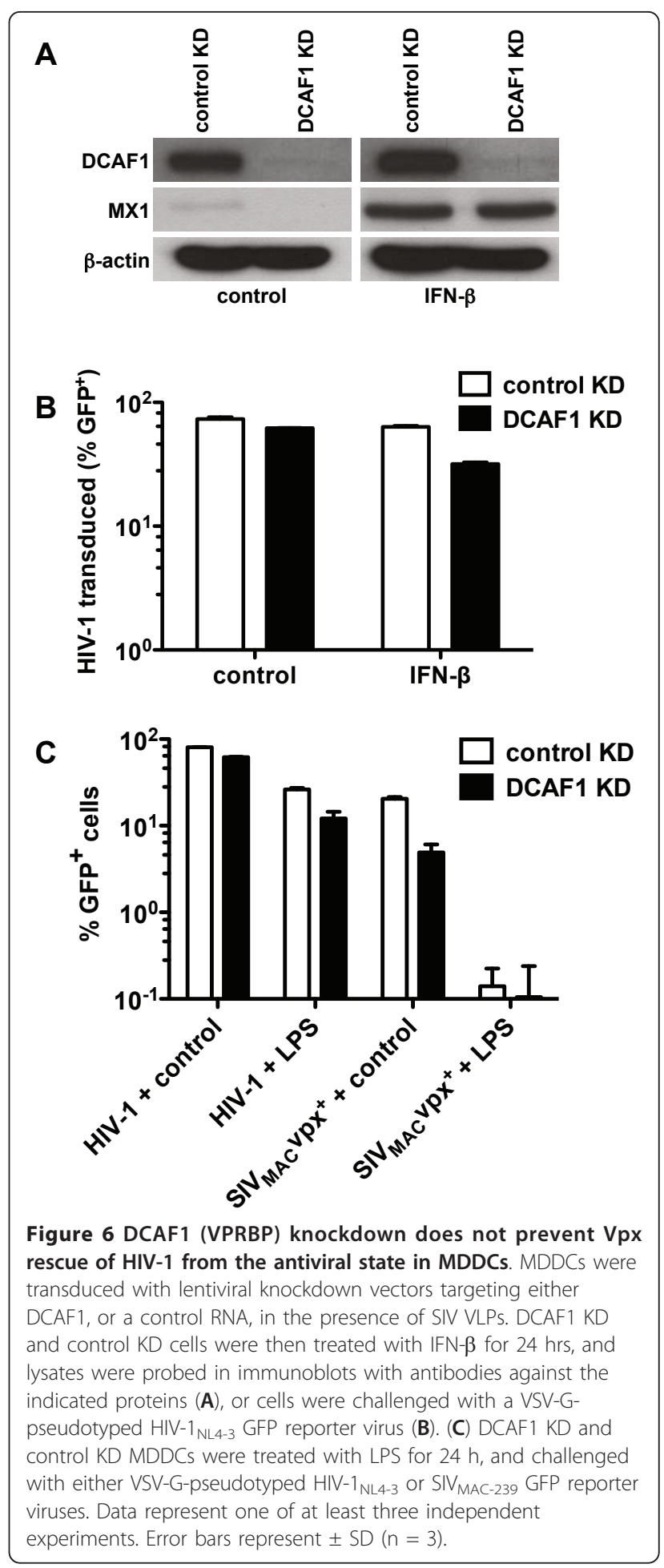

Parallel experiments in MDDCs from the same donor showed that transduction with SIV $_{\text {MAC }}$ was efficiently blocked by IFN- $\beta$ or by LPS (Figure $6 \mathrm{C}$ ), demonstrating that the antiviral state had been well-established in these cells. 
The IFN-specific, vpx-sensitive block to HIV-1 is in the MDDC nucleus

$\mathrm{Vpx}$ is required for the synthesis of $\mathrm{SIV}_{\mathrm{MAC}}$ or HIV-2 cDNA after infection of MDDCs or MDMs [10,13,14]. VLPs bearing Vpx similarly increase the levels of nascent HIV-1 cDNA after infection of these cell types [10]. In the absence of exogenous IFN, $\mathrm{Vpx}^{+}$VLPs indeed increased the levels of full-length linear HIV-1 cDNA (Figure 7A). The increase in the levels of 2-LTR circles (Figure 7B) and Alu-PCR products (Figure 7C) were of comparable magnitude. Heat-inactivated virus and virions generated in the absence of Env were used as controls to demonstrate that the PCR products were a reflection of de novo cDNA synthesis in the target cells and were not the result of contaminating plasmid DNA carried over from the transfection used to generate the viruses. These experiments indicate that, in the absence of exogenous IFN, the main effect of $\mathrm{Vpx}$ is to increase the efficiency of HIV-1 reverse transcription.

When MDDCs were treated with IFN- $\alpha$ prior to challenge with HIV-1, the magnitude rescue of full-length viral cDNA and 2-LTR circles by Vpx was identical to the magnitude rescue by $\mathrm{Vpx}$ in the absence of
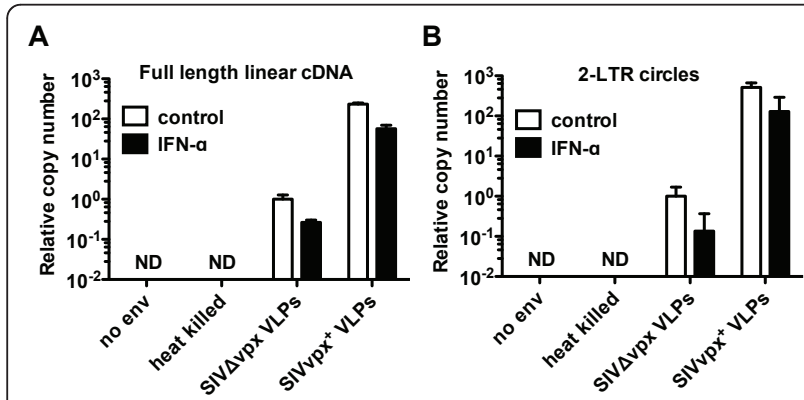

C
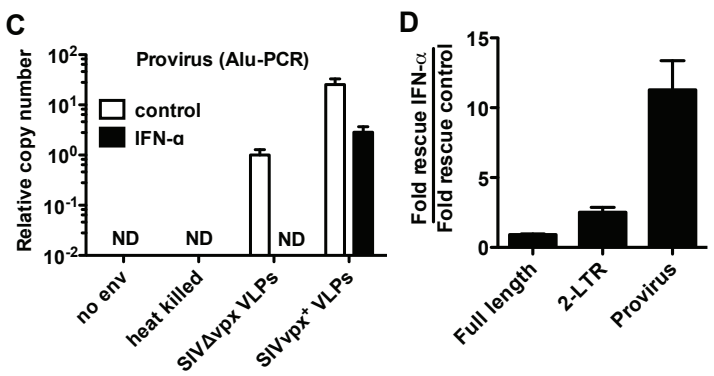

Figure 7 SIV $_{\text {MAC }}$ Vpx rescues HIV-1 from the antiviral state in MDDC prior to establishment of the provirus. MDDCs were treated with IFN- $\alpha$ for $24 \mathrm{~h}$, and then treated with SIV MAC VLPS or media for $3 \mathrm{~h}$, and finally challenged with a VSV-G-pseudotyped

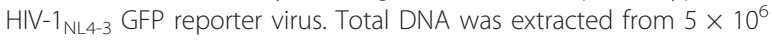
MDDCs and qPCR was performed for HIV-1 full-length linear reverse transcription products (A), 2-LTR circles (B), and provirus (C). (D) Data from A, B, C, represented as (fold-rescue of HIV-1 by Vpx from IFN- $\alpha$ treatment) divided by (fold-rescue of HIV-1 by Vpx in the absence of exogenous IFN). Data represent one of at least three independent experiments. Error bars represent \pm SEM $(n=4)$. exogenous IFN (Figure 7D). In contrast, the magnitude rescue of proviral DNA by $\mathrm{Vpx}$ was at least 12 -fold greater when MDDCs had been treated with exogenous IFN than with untreated MDDCs (Figure 7C and 7D). The magnitude of this rescue possibly underestimates the real difference, since the Alu-PCR signal was below the limit of detection when DNA from IFN-treated cells was used as template, even after 50 cycles of amplification. These data indicate that the IFN-specific effect of Vpx in MDDCs occurs after the preintegration complex is transported to the MDDC nucleus.

\section{Conclusions}

The experiments presented here demonstrate that SIVMAC/HIV-2 Vpx rescues HIV-1 from the antiviral state established by exogenous type I IFN or LPS in MDDCs. This phenotype is truly extraordinary in that $\mathrm{Vpx}$ offered complete rescue of HIV-1, after the antiviral state had been fully established, and the magnitude of the rescue approached 1000-fold. Surprisingly, the presence of $\mathrm{Vpx}$ in SIV $\mathrm{MAC}$ or HIV-2 did not protect these viruses from IFN- $\beta$ or LPS treatment, even when target cell MDDCs were treated with VLPs bearing additional Vpx prior to challenge with reporter virus. Although $\mathrm{Vpx}$ is not normally an HIV-1 accessory protein, it provides a powerful tool that will aid attempts to identify new HIV-1 restriction factors that are elicited by IFN in dendritic cells.

Elucidation of the mechanism by which Vpx rescues HIV-1 from the antiviral state would be aided enormously by an experimental system that exploits a cell line. Among cell lines tested, the most pronounced phenotype was observed with the acute monocytic leukemia cell line THP-1 [47], which had been treated with phorbol esters to promote differentiation into macrophages, as we reported previously to study $\mathrm{Vpx}$ and innate immune signaling $[11,39]$. The magnitude inhibition of HIV- 1 transduction by LPS or IFN- $\beta$ in THP-1 macrophages [11,39] was 10-fold less than that seen in MDDC. Of greater concern, though, rescue of HIV-1 from the antiviral state by $\mathrm{Vpx}^{+}$VLPs in these cells was only 2 to 10 -fold (data not shown). Ongoing mechanistic studies concerning the Vpx phenotype reported here, then, will likely not be possible with a cell line.

HIV-1 transduction of monocyte-derived macrophages (MDMs) was also greatly stimulated by Vpx; although, in the absence of exogenous IFN, HIV-1 transduction efficiency was lower in these cells than in MDDCs (data not shown). A necessary consequence is that a smaller proportion of the Vpx effect in MDMs was specific to the antiviral state. In other words, the magnitude rescue of HIV-1 by Vpx following establishment of the antiviral state with exogenous IFN was most evident in MDDCs. In the presence of exogenous type 1 IFN, MDDCs 
might express an HIV-1-specific, Vpx-sensitive, antiviral effector at higher levels than do MDMs. Alternatively, constitutive expression levels of this putative factor might be higher in MDMs.

Viruses often encode factors that prevent establishment of the antiviral state. For example, hepatitis $\mathrm{C}$ virus, poliovirus, and rhinovirus proteases degrade MDA-5, RIG-I, IPS-1, and TRIF [48-53]. In the experimental system reported here, $\mathrm{Vpx}$ was administered after the antiviral state was fully established. Therefore, Vpx does not act by blocking induction of the antiviral state. This is consistent with the observation that $v p x$ had no significant effect on the transcriptional induction of luciferase reporters for critical innate immune factors, including IFN $-\beta$, NF- $\kappa \mathrm{B}$, or AP-1 (additional file 4, Figure S4).

Additionally, Vpx appears not to launch a global shutdown of the antiviral state. It caused no change in levels of MDDC cell surface markers for maturation, in IFN- $\beta$ secretion and steady-state protein levels for MX1 and APOBEC3A, or in steady-state levels of mRNAs produced by 8 ISGs (additional file 1, Figure S1). More importantly, Vpx did not rescue SIV $\mathrm{SAC}_{\mathrm{MA}}$ or HIV-2, indicating that the antiviral state was very much intact following exposure to Vpx. More likely, Vpx inactivates an HIV-1-specific antiviral effector that is induced by IFN. This inactivation might involve degradation, the same way that Vif promotes the degradation of APOBEC3G [30-32] or $\mathrm{Vpu}$ promotes the degradation of TETHERIN [54-56]. Alternatively, Vpx might sequester the putative factor, blocking it without assistance from ubiquitination machinery, as may also be the case with Vif and Vpu [57,58].

Though it has been known for over 20 years that type 1 IFN and LPS block HIV-1 infection of myeloid cells [40], the effector proteins responsible for the block to HIV-1 transduction of IFN-treated MDDCs is not known. Several ISG-encoded proteins inhibit HIV-1, APOBEC3G [59] and Tetherin [60,61] being prominent among them. These host restriction factors pose obstacles to infection of sufficient importance that HIV-1 maintains two of its nine genes - vif and $v p u$, respectively - to counteract them. Neither Vif nor Vpu is required for the phenotype reported here since Vpx rescued minimal HIV-1 vectors lacking all viral accessory proteins as efficiently as it rescued full HIV-1 virus. Additionally, the best-characterized phenotypes of Vif and $\mathrm{Vpu}$ require their presence during virion assembly and the experiments reported here likely involve effects of $\mathrm{Vpx}$ that are restricted to the target cell.

TRIM5, another restriction factor encoded by an ISG, is required for establishment of an antiviral state by LPS in MDDCs [39]. Nonetheless, endogenous human TRIM5 is unlikely to be a direct antiviral effector in the experiments reported here since inhibition of HIV-1 transduction by exogenous type 1 IFN is not reversed by TRIM5 knockdown [39]. Other TRIM proteins are encoded by ISGs [62], and some of these exhibit antiviral activity [63]. TRIM22, for example, blocks HIV-1 LTR-directed transcription [64], but the putative antiviral effector in IFN-treated MDDCs acts before integration, as documented by Alu-PCR (Figure 7). Additionally, TRIM22 does not block transcription from the heterologous promoter (SFFVp) used in the transduction vectors here [64].

In the course of examining ISG expression levels in MDDCs it was observed that, in response to exogenous type 1 IFN or LPS, APOBEC3A mRNA levels increased nearly 10,000-fold and the protein levels also increased to an impressive extent (additional file 1, Figure S1C). APOBEC3A is a nuclear protein $[65,66]$ and therefore a reasonable candidate for the $\mathrm{Vpx}$-sensitive, IFN-stimulated, anti-HIV-1 effector protein. Specific association of APOBEC3A with Vpx was not detected in co-transfection experiments in $293 \mathrm{~T}$ cells, and no effect on inhibition of HIV-1 was observed when APOBEC3A knockdown was attempted with lentiviral vectors or with transfected double-stranded RNA oligonucleotides (data not shown). These findings are in contrast to reports that $\mathrm{Vpx}$ associates with APOBEC3A and that a $v p x$ mutant that does not bind to APOBEC3A failed to stimulate HIV-1 infection of monocytes [67]. APOBEC3A knockdown was also reported to render monocytes more permissive for HIV-1 [68]. These discrepancies with the results reported here might be due to cell type differences, i.e, monocytes versus MDDCs, or other differences in methodology.

Vpx was recently shown to bind to SAMHD1 and promote the degradation of this myeloid cell protein $[69,70]$. While SAMHD1 is clearly a Vpx-sensitive inhibitor of HIV-1 replication in myeloid cells, it does not appear to be the IFN-stimulated HIV-1 inhibitor described here. SAMHD1 knockdown in THP-1 cells results in more than 10-fold increase in HIV-1 replication [70]; in contrast to the enormous effect of $\mathrm{Vpx}$ in IFN-treated MDDCs, HIV-1 infection of IFN-treated THP-1 cells increases only two to three-fold in response to Vpx.

Both Vpr and Vpx bind DCAF1 (VPRBP) and associate with the DDB1/RBX1/CUL4A E3 ubiquitin ligase complex [12,13,15,33-37,71,72]. Vpr might, therefore, be expected to interfere with Vpx binding to DCAF1 and the E3 complex. However, the presence of HIV-1 Vpr or $\operatorname{SIV}_{\text {MAC }}$ Vpr did not significantly alter the ability of SIV $_{\text {MAC }}$ Vpx to protect HIV-1 from the antiviral state, underlying the unique ability of Vpx to protect HIV-1.

The unexpected finding that $\mathrm{Vpx}$ mutant proteins that do not bind to DCAF1 (Figure 5A and references 
$[12,13,15,35])$ retain the ability to rescue HIV-1 from exogenous IFN indicates that the DCAF1/DDB1/RBX1/ CUL4A E3 ubiquitin ligase complex is dispensable for the phenotype reported here. Consistent with this result was the demonstration that Vpx rescued HIV-1 in the presence of an effective DCAF1 knockdown (Figure 6). While the DCAF1/DDB1/RBX1/CUL4A E3 ubiquitin ligase complex, and $\mathrm{Vpx}$, is clearly required for $\mathrm{SIV}_{\mathrm{MAC}}$ to infect human macrophages in the absence of exogenous type 1 IFN [12], Vpx interaction with DCAF1 was also not required for HIV-1 transduction of THP-1 macrophages [11]. These results indicate that, if $\mathrm{Vpx}$ rescues HIV-1 from the antiviral state by promoting the degradation of an antiviral effector, it does so by recruiting a yet-to-be-identified E3 ubiquitin ligase complex.

As previously reported $[10,13,14]$, Vpx had a large effect on HIV-1 reverse transcription in transduced MDDCs (Figure 7). An additional effect of Vpx was observed, though, that was specific to the cells that had been treated with exogenous type 1 IFN: Vpx overcame a block to HIV-1 transduction that occurred after the virus had entered the target cell nucleus (Figure 7). Thus, it may be that Vpx protects HIV-1 from more than one antiviral factor. The first factor is constitutively expressed in myeloid cells and blocks reverse transcription. The second factor is induced by IFN and acts in the nucleus to block transduction. HIV-1 CA and IN, two proteins essential at this stage of the HIV-1 replication cycle $[28,73,74]$, would be likely targets of this antiviral factor. To date, attempts to demonstrate the importance of these proteins by transferring Vpx-responsiveness using chimeric viruses have not been successful due to the poor infectivity of these constructs in highly permissive cell lines, let alone in MDDCs.

Why does Vpx protect HIV-1, and not SIV MAC or HIV-2, from the antiviral state in MDDCs? A number of scenarios are possible. It might be that there is an IFN-inducible, HIV-1-specific inhibitor, which is suppressed by Vpx. This factor might be induced by the recently reported HIV-1-specific, cryptic sensor in MDDCs [75]. In this case, one would need to invoke an

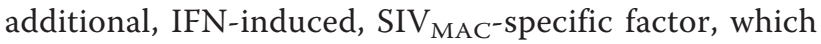
is not suppressed by Vpx. Alternatively, there might be a single IFN-induced inhibitor of both viruses, from which Vpx offers protection to HIV-1 but not to SIVMAC. Whichever scenario is correct, identification of antiviral factors such as these has the potential to guide development of new drugs for inhibiting HIV-1 replication in the clinical context. Additionally, given the critical role of dendritic cells at the interface between the innate and acquired immune systems [76,77], identification of such factors may aid attempts to understand how the innate immune system detects HIV-1, and assist efforts to stimulate acquired immune responses to HIV-1 [39,78].

\section{Methods}

\section{Ethics statement}

Buffy-coats obtained from anonymous blood donors were provided by the Blood Transfusion Center of the Hematology Service of the University Hospital of Geneva by agreement with the Service, after approval of our project by Ethics Committee of the University Hospital of Geneva (Ref\# 0704).

\section{Chemicals and drugs}

The following compounds were used at the given final concentrations: Ultrapure LPS from E. coli K12 (100 ng/ $\mathrm{mL})$, poly(I:C) $(25 \mu \mathrm{g} / \mathrm{mL}$, or $2 \mu \mathrm{g} / \mathrm{mL}$ when complexed with Lipofectamine 2000 (Invitrogen)), and poly(dA:dT) $(2 \mu \mathrm{g} / \mathrm{mL})$ were obtained from Invivogen. Recombinant, human IFN- $\beta$ (10 ng/mL) and recombinant, human IFN- $\alpha 2 \mathrm{a}(10 \mathrm{ng} / \mathrm{mL})$ were obtained from PBL InterferonSource. All other chemicals and drugs were obtained from Sigma-Aldrich, unless otherwise noted.

\section{Cell lines and primary cell cultures}

HEK-293 and 293T cells were obtained from American Type Culture Collection (ATCC) and were grown in Dulbecco's modified Eagle medium (D-MEM) (high glucose) (Invitrogen) supplemented with 10\% fetal bovine serum (FBS) (Hyclone), $1 \times$ MEM Non-Essential Amino Acids (NEAA) Solution (Invitrogen), and $1 \times$ GlutaMAX-I (Invitrogen). 293T cells were periodically grown in cell culture medium containing $500 \mu \mathrm{g} / \mathrm{mL}$ Geneticin (Invitrogen) to maintain expression of the SV40 large T antigen.

THP-1 cells were obtained from ATCC and maintained in RPMI-1640 (Invitrogen) supplemented with 10\% FBS, $20 \mathrm{mmol} / \mathrm{L}$ HEPES (Invitrogen), $1 \times \mathrm{MEM}$ NEAA, and $1 \times$ GlutaMAX-I. In order to differentiate THP-1 monocytes into macrophage-like cells, THP-1 cells were counted, centrifuged at $200 \times g$ for $10 \mathrm{~min}$, and resuspended at a concentration of $1 \times 10^{6}$ cells $/ \mathrm{mL}$ in fresh cell culture medium containing $100 \mathrm{ng} / \mathrm{mL}$ phorbol 12-myristate 13-acetate (PMA). Cells were plated into each well of a sterile tissue culture plate $(2 \mathrm{~mL}$ culture/well of a 6-well plate or $200 \mu \mathrm{L}$ culture/well of a 96-well flat-bottom plate) and allowed to differentiate for $24 \mathrm{~h}$, at which point the PMA-containing medium was removed and fresh cell culture medium (without PMA) was added. The cells were rested for an additional $48 \mathrm{~h}$ before use.

Peripheral blood mononuclear cells (PBMCs) were isolated from buffy coats prepared from healthy, anonymous donors using Ficoll-Paque Plus (GE Healthcare) following the protocol supplied by Miltenyi Biotec. 
$\mathrm{CD} 14^{+}$cells (monocytes) were enriched from PBMCs by positive selection using CD14 MicroBeads (Miltenyi Biotec) with purity routinely greater than $95 \%$, as determined by flow cytometry after staining with PE antihuman CD14 (BD Biosciences). Enriched CD14 ${ }^{+}$cells were counted, centrifuged at $200 \times g$ for $10 \mathrm{~min}$, and resuspended in RPMI-1640 supplemented with $10 \%$ FBS, $20 \mathrm{mmol} / \mathrm{L}$ HEPES, $1 \times$ MEM NEAA, and $1 \times$ GlutaMAX-I, at a concentration of $1 \times 10^{6}$ cells $/ \mathrm{mL}$. In order to generate monocyte-derived macrophages (MDM), recombinant, human GM-CSF (R\&D Systems) was added to the cell suspension to a final concentration of $50 \mathrm{ng} / \mathrm{mL}$, and in order to generate monocyte-derived dendritic cells (MDDC), recombinant, human IL-4 (R\&D Systems) was added to a final concentration of 25 $\mathrm{ng} / \mathrm{mL}$ along with $50 \mathrm{ng} / \mathrm{mL}$ GM-CSF. CD14 ${ }^{+}$cells were allowed to either differentiate into MDDCs in the presence of GM-CSF and IL-4 for $4 \mathrm{~d}$, or into MDMs in the presence of GM-CSF alone for $10 \mathrm{~d}$, before use. The following antibodies were used for flow cytometry: APC anti-CD86 (BU63) was from EXBIO; FITC anti-CD1a (HI149), PE anti-CD209 (DC-SIGN) (DCN46), and $\mathrm{APC}$-anti-CD83 (HB15e) were from BD Biosciences. Isotype controls were from Miltenyi Biotec.

All primary cells and cultured cell lines were maintained in cell culture media without penicillin or streptomycin, and were cultured at $37^{\circ} \mathrm{C}$ in a humidified incubator containing $5 \%$ carbon dioxide.

\section{Plasmids, Vectors, and Viruses}

SIV $_{\text {MAC-251 }} v p x$, HIV-2 ROD $v p x$, SIV $_{\text {SMM-PBj }} v p x$, and SIV $_{\text {AGM-TAN }} v p r$ were codon-optimized for expression in human cells using services provided by Sloning BioTechnology GmbH (Puchheim, Germany). See additional file 5, Table S1 for the codon-optimized nucleic acid sequences. The codon optimized cDNAs were cloned into pcDNA3.1(-) (Invitrogen) by PCR using the primer pairs listed in additional file 6, Table S2. Alanine substitution mutations were introduced into the codonoptimized SIV MAC-251 $_{1 p x}$ cDNA by overlapping PCR, using the primer sets detailed in additional file 6, Table S2. APOBEC3A, APOBEC3A:Myc: 6 × His, APOBEC3G, and APOBEC3G:Myc:6 $\times$ His expression constructs were provided by Dr. Klaus Strebel (National Institute of Allergy and Infectious Diseases, NIH). FLAG:HA: AU1:DCAF1 and FLAG:HA:AU1:DDB1 expression constructs were provided by Dr. Jacek Skowronski (Case Western Reserve University).

pFSGW, an HIV-1-based transfer vector with EGFP expression under the control of the spleen focus-forming virus (SFFV) long terminal repeat (LTR), as well as gag-pol and VSV G expression plasmids, are described elsewhere [39]. pSIV3+, a SIV MAC-251 $_{\text {gag-pol expression }}$ plasmid [79], and pSIV3+ $+\Delta v p x$, generated by digest with
BstB1 and religation after blunting ends with DNA Polymerase I, Large (Klenow) Fragment (New England BioLabs), introducing a premature stop codon at amino acid 25 of $v p x$, were provided by Dr. Andrea Cimarelli (École Normale Supérieure de Lyon). pNL4-3 $\mathrm{Nef}_{\mathrm{NA} 7}$ : GFP (CCR5-tropic), which bears the V3 loop of the CCR5-tropic 92TH014-2 HIV-1 strain and where $\mathrm{Nef}_{\mathrm{NA} 7}$ is fused to EGFP [80,81]. pNL4-3.GFP.E- [82] and pNL4-3.Luc.E- [83] are pNL4-3 with an env inactivating mutation and EGFP or luciferase, respectively, cloned in place of nef. The HIV-2 and HIV-2 $2 v p x$ packaging plasmids, as well as the HIV-2 GFP transfer vector, are described elsewhere [10]. p8.9NDSB is a minimal HIV-1 packaging plasmid [84]. The SIV MAC Vpx binding motif (DPAVDLL) was generated and introduced into HIV-1 Gag p6 by overlapping PCR and cloned into the BglII and Bcll sites of p8.9NDSB using the following primers: p6 BglII 5': 5'-TAGGGAAGATCTGGCCTTCCCACAA-3', p6 Vpx ins 3': 5'-TAGCAGATCCACAGCTGGGTCTTCTGGTGGGGCTG TTGGCTCTGG-3', p6 Vpx ins 5': 5'-GACCCAG CTGTGGATCTGCTAGAGAGCTTCAGGTTTGGGGA AGA-3', p6 BclI 3': 5'-ATGAGTATCTGATCATACT GTCTTACTT-3'. SIV MAC-239 env $^{-}$GFP is described elsewhere [85]. psSIV-GAE is pSIV-GAE [86], a SIVMAC-251 transfer vector expressing GFP, where the cytomegalovirus (CMV) promoter driving EGFP expression was replaced with the SFFV LTR, amplified by PCR from $\mathrm{pFSGW}$.

\section{Production of viruses, vectors, and virus-like particles (VLPs)}

Viruses, minimal vectors, and VLPs were produced by transfection of 293T cells using Lipofectamine 2000 (Invitrogen), according to the manufacturer's instructions. For three-part vector systems, the following DNA ratio was used: 4 parts transfer vector: 3 parts packaging plasmid: 1 part envelope. For two-part virus systems a 7:1 ratio was used (7 parts env virus: 1 part envelope). For VLPs, a 7:1 ratio was used (7 parts gag-pol expression plasmid: 1 part envelope). $16 \mathrm{~h}$ after transfection the transfection medium was replaced with fresh target-cell medium. $48 \mathrm{~h}$ after transfection the supernatant was collected, centrifuged at $200 \times g$ for $5 \mathrm{~min}$, filtered through a sterile $0.45 \mu \mathrm{m}$ syringe filter (Millipore), and stored in $1 \mathrm{~mL}$ aliquots at $-80^{\circ}$ C. When comparing viruses, vectors, or VLPs, samples were normalized by single-cycle infectivity assays on HEK293 cells and/or the reverse transcriptase (RT) activity present in the viral supernatant by qRT-PCR [87].

\section{RNAi in primary human monocyte-derived dendritic cells and macrophages}

To generate stable microRNA-based shRNA knockdowns in primary human MDDC or MDM, human 
CD14 ${ }^{+}$cells, freshly isolated from PBMC as described

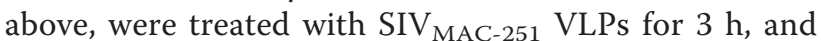
then transduced with either a control or experimental pAPM microRNA-based shRNA vectors [39]. The CD14 ${ }^{+}$cells were then allowed to differentiate into MDDC or MDM as described above. After differentiation, the MDDC or MDM were selected with $10 \mu \mathrm{g} / \mathrm{mL}$ puromycin dihydrochloride for $3 \mathrm{~d}$ and assayed for knockdown by SDS-PAGE/western blot and/or qRT-PCR analysis. Using this technique we routinely observed greater than $90 \%$ transduced MDDC or MDM. shRNA target sequences used: Luciferase: 5'-TACAAACGCTCTCATCGACAAG-3', APOBEC3A 5'-TTGGCTTCATATCTAGACTAAC-3', DCAF1 (VPRBP): 5'AGCACTTCAGATTATCATCAAT-3'.

For transient siRNA in MDM, $5 \times 10^{5}$ cells were plated in each well of a 6 -well plate. $600 \mathrm{pmol}$ of ONTARGETplus siRNA Smart pools (Thermo Scientific Dharmacon) targeting DCAF1, APOBEC $3 A$, or control siRNA were complexed with $5 \mu \mathrm{L}$ Lipofectamine 2000 (Invitrogen), following the manufacturer's instructions, and added to $2 \mathrm{~mL}$ of cell culture media. The transfection medium was removed after $6 \mathrm{~h}$ and replaced with fresh cell culture medium. Knockdown was assessed by SDS-PAGE/western blot and/or qRT-PCR analysis 48-72 $\mathrm{h}$ after transfection. For transient siRNA in MDDC, $8 \times$ $10^{5}$ were plated in each well of a 12-well plate in 600 $\mu \mathrm{L}$ culture medium. $100 \mathrm{nM}$ of FlexiTube GeneSolutions pooled siRNAs (Qiagen) targeting DCAF1, APO$B E C 3 A$, or control siRNA were complexed with $6 \mu \mathrm{L}$ of HiPerFect Transfection Reagent (Qiagen), following the manufacturer's instructions, and added to the MDDC culture. A second round of transfection was performed $24 \mathrm{~h}$ later. Knockdown was assessed by SDS-PAGE/western blot and/or qRT-PCR analysis 24-48 $\mathrm{h}$ after the second transfection.

\section{Quantitative reverse transcription polymerase chain reaction (qRT-PCR)}

Total RNA was extracted from $2 \times 10^{6}$ cells using the RNeasy Plus Mini Kit (Qiagen), following the manufacturer's instructions. First-strand cDNA was generated using the SuperScript III First-Strand Synthesis System (Invitrogen) using $2 \mu \mathrm{g}$ total RNA and random hexamers, according to the manufacturer's protocol. The qPCR reaction was performed in triplicate in a $20 \mu \mathrm{L}$ volume using $1 \times$ TaqMan Gene Expression Master Mix (Applied Biosystems), $1 \mu \mathrm{L}$ of undiluted cDNA, and 1 $\mu \mathrm{L}$ of the specified TaqMan Gene Expression Assay (Applied Biosystems) on either the 7900HT Fast RealTime PCR System (Applied Biosystems) or the CFX96 Real Time System/C1000 Thermal Cycler (Bio-Rad) using the following program: $95^{\circ} \mathrm{C}$ for $10 \mathrm{~min}$ and 45 cycles of $95^{\circ} \mathrm{C}$ for $15 \mathrm{~s}$ and $60^{\circ} \mathrm{C}$ for $1 \mathrm{~min}$. The following TaqMan Gene Expression Assays were used: APOBEC3A (Hs00377444_m1), APOBEC3G (Hs00 222415_m1), CCL2 (Hs00234140_m1), CCL8 (Hs00 271615_m1), CUL4A (Hs00757716_m1), CXCL10 (Hs00 171042_m1), DDB1 (Hs00172410_m1), IFIT1 (Hs00 356631_g1), IFIT2 (Hs00533665_m1), IFNB1 (Hs01 077958_s1), IL6 (Hs00985639_m1), MX1 (Hs00 182073_m1), PTGS2 (Hs00153133_m1), TNF (Hs00 174128_m1), TRIM5 (Hs01552558_m1), and VPRBP (Hs00206762_m1). OAZ1 (Hs00427923_m1) was used as an endogenous control. Data were analyzed using the SDS software v2.2.2 (Applied Biosystems) or the CFX Manager software v1.6 (Bio-Rad), which calculate relative mRNA expression levels using the standard comparative Ct method $\left(2^{-\Delta \Delta \mathrm{Ct}}\right)$ with error bars representing \pm the standard error of the mean.

\section{Sodium dodecyl sulfate polyacrylamide gel electrophoresis (SDS-PAGE)/western blot analysis}

$2 \times 10^{6}$ cells were lysed in $200 \mu \mathrm{L} 1 \times$ Laemmli sample buffer $(62.5 \mathrm{mmol} / \mathrm{L}$ Tris, pH 6.8, 2\% SDS, 10\% glycerol, $357.5 \mathrm{mmol} / \mathrm{L}$ 2-mercaptoethanol (2-ME), $0.0025 \%$ bromophenol blue (Bio-Rad)), supplemented with $1 \times$ Halt Protease and Phosphatase Inhibitor Cocktail, EDTA-free (Thermo Fisher Scientific) and $5 \mathrm{mmol} / \mathrm{L}$ EDTA, $\mathrm{pH}$ 8.0. Whole-cell lysates were heated at $100^{\circ} \mathrm{C}$ for $5 \mathrm{~min}$, centrifuged at $14,000 \times g$ for $2 \mathrm{~min}$, and $50 \mu \mathrm{L}$ were loaded onto a $10 \%$ ProSieve 50 gel (Lonza) for SDSPAGE. Relative protein concentration was normalized after staining the gel with SimplyBlue SafeStain (Invitrogen). After SDS-PAGE, proteins were transferred onto an Immun-Blot polyvinylidene fluoride (PVDF) membrane (Bio-Rad) for $16 \mathrm{~h}$ at $30 \mathrm{~V}$ (constant voltage) at $4^{\circ}$ C. After the protein transfer, the membrane was washed $3 \times 5$ min with deionized water and blocked $1 \mathrm{~h}$ at $4^{\circ} \mathrm{C}$ with $5 \%$ non-fat dry milk dissolved in TBST (Tris-buffered saline $(50 \mathrm{mmol} / \mathrm{L}$ Tris, $\mathrm{pH} 7.4,150 \mathrm{mmol} / \mathrm{L}$ sodium chloride $(\mathrm{NaCl})$ ) with $0.1 \%$ Polysorbate 20 (Tween 20)). The membrane was then washed $3 \times 5$ min with TBST. The primary antibody was diluted to 1 $\mu \mathrm{g} / \mathrm{mL}$ in $5 \%$ non-fat dry milk dissolved in TBST and added to the membrane and incubated $16 \mathrm{~h}$ at $4^{\circ} \mathrm{C}$ with gentle rocking. After the $16 \mathrm{~h}$ incubation with the primary antibody the membrane was washed $3 \times 5 \mathrm{~min}$ with TBST. The secondary antibody was diluted $1: 10,000$ in $5 \%$ non-fat dry milk dissolved in TBST and added to the washed membrane and incubated at room temperature for $1 \mathrm{~h}$ with gentle rocking. The membrane was washed $3 \times 10 \mathrm{~min}$ and developed using either the ECL or ECL Plus Western Blotting Detection Reagents (GE Healthcare Life Sciences) and exposed to Hyperfilm ECL film (GE Healthcare Life Sciences).

The following antibodies were used in this study: rabbit anti-VPRBP (DCAF1) and rabbit anti-MX1 were 
from Proteintech Group; rabbit anti-APOBEC3A/APOBEC3G serum was a generous gift from Dr. Klaus Strebel (National Institute of Allergy and Infectious Diseases, NIH); mouse anti-FLAG (M2), rabbit antiFLAG, mouse anti c-Myc (9E10), rabbit anti-c-Myc, mouse anti-HA (HA-7), rabbit anti-HA, and mouse anti- $\beta$-Actin (AC-74) were from Sigma-Aldrich. The following reagents were obtained through the AIDS Research and Reference Reagent Program, Division of AIDS, NIAID, NIH: monoclonal antibody to HIV-1 p24

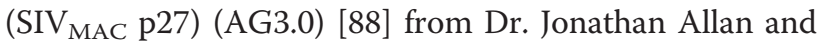
HIV-2 Vpx Monoclonal Antibody (6D2.6) [89] from Dr. John C. Kappes. Secondary antibodies used: HRP-linked donkey anti-rabbit IgG and HRP-linked sheep antimouse IgG were from GE Healthcare Life Sciences.

\section{Immunoprecipitation (IP)}

Sub-confluent 293T cells grown on T-75 tissue culture flasks were transfected with $16 \mu \mathrm{g}$ total plasmid DNA using TransIT-LT1 Transfection Reagent (Mirus Bio), following the manufacturer's protocol. $40 \mathrm{~h}$ post-transfection, cells were washed with $30 \mathrm{~mL}$ ice-cold phosphate buffered saline (PBS) (Invitrogen) and lysed with 1 $\mathrm{mL}$ ice-cold lysis buffer $(50 \mathrm{mmol} / \mathrm{L}$ Tris, $\mathrm{pH} 7.4,150$ mmol/L NaCl, 0.5\% CHAPSO (Affymetrix)) supplemented with $1 \times$ Halt Protease and Phosphatase Inhibitor Cocktail, EDTA-free (Thermo Fisher Scientific). Crude cell lysates were scraped off the surface of the flask, transferred to pre-chilled $2 \mathrm{~mL}$ microcentrifuge tubes, and rotated at $4^{\circ} \mathrm{C}$ for $20 \mathrm{~min}$. The crude cell lysates were then centrifuged at $14,000 \times g$ for $10 \mathrm{~min}$ and 900 $\mu \mathrm{L}$ of the clarified lysate was transferred to pre-chilled microcentrifuge tubes, and the remaining $100 \mu \mathrm{L}$ of the clarified lysate was diluted equally in $2 \times$ Laemmli sample buffer, incubated at $100^{\circ} \mathrm{C}$ for $5 \mathrm{~min}$, and stored at $-80^{\circ} \mathrm{C}$. $2 \mu \mathrm{g}$ antibody was conjugated to $50 \mu \mathrm{L}$ of Protein G Dynabeads (Invitrogen) following the manufacturer's protocol. The beads were washed 3 times with $1 \mathrm{~mL}$ ice-cold lysis buffer, resuspended in $100 \mu \mathrm{L}$ lysis buffer, and added to the clarified cell lysates. After $2 \mathrm{~h}$ rotating at $4^{\circ} \mathrm{C}$, the Protein $\mathrm{G}$ magnetic bead immune complexes were washed 4 times with $1 \mathrm{~mL}$ ice-cold lysis buffer, resuspended in $100 \mu \mathrm{L}$ of $1 \times$ Laemmli sample buffer, incubated at $100^{\circ} \mathrm{C}$ for $5 \mathrm{~min}$, and stored at $-80^{\circ} \mathrm{C}$ until ready for SDS-PAGE.

\section{Vpx incorporation assay}

Using TransIT-LT1 Transfection Reagent (Mirus Bio), sub-confluent $293 \mathrm{~T}$ cells grown on T-75 flasks were transfected with the following plasmids: for SIV $\mathrm{VAC}_{\text {MAC }}$ Vpx incorporation in HIV-1, $14 \mu \mathrm{g}$ p8.9NDSB (containing HIV-1 Gag WT) or p8.9NDSB-DPAVDLL (containing HIV-1 Gag with the SIV MAC Vpx binding motif inserted into p6) along with $2 \mu \mathrm{g}$ empty pcDNA3.1(-) or
pcDNA3.1(-) expressing codon-optimized SIV MAC-251 $_{1}$ $v p x$ WT; for SIV $\mathrm{SAC}_{\mathrm{MA}} \mathrm{Vpx}$ incorporation into SIVMAC-251, $14 \mu \mathrm{g}$ pSIV3 $+\Delta v p x$ and $2 \mu \mathrm{g}$ empty pcDNA3.1 (-) or pcDNA3.1(-) expressing codon-optimized SIVMAC-251 $v p x$ WT or the indicated mutants. $40 \mathrm{~h}$ after transfection, the medium was collected, clarified by centrifugation for $10 \mathrm{~min}$ at $500 \times g$, and filtered through a sterile $0.45 \mu \mathrm{m}$ syringe filter (Millipore). The supernatant was then overlaid on $8 \mathrm{~mL}$ of TNE buffer $(50$ $\mathrm{mmol} / \mathrm{L}$ Tris $\mathrm{pH} 7.5,140 \mathrm{mmol} / \mathrm{L} \mathrm{NaCl}, 5 \mathrm{mmol} / \mathrm{L}$ EDTA, pH 8.0) containing $25 \%(\mathrm{w} / \mathrm{v})$ sucrose in a 30 $\mathrm{mL}$ Beckman Coulter ultracentrifuge tube, and subjected to $26,000 \mathrm{rpm}$ for $90 \mathrm{~min}$. The supernatant was then removed and the pellet was dissolved in $1 \times$ Laemmli sample buffer, heated at $100^{\circ} \mathrm{C}$ for $5 \mathrm{~min}$, and stored at $-80^{\circ} \mathrm{C}$ until SDS-PAGE.

\section{Luciferase assays}

HEK-293 cells were plated on white, opaque 96-well CulturPlate-96 microplates (PerkinElmer) at a concentration of $2 \times 10^{4}$ cells per $100 \mu \mathrm{L}$ tissue culture medium per well, $24 \mathrm{~h}$ prior to transfection. Cells were transfected with Lipofectamine 2000, using $0.5 \mu \mathrm{L}$ Lipofectamine 2000 per well, with $1 \mathrm{ng}$ of the Renilla luciferase internal control reporter plasmid pRL-TK (Promega), 5 ng firefly luciferase experimental reporter plasmid, and 15 to $50 \mathrm{ng}$ of pcDNA3.1(-) containing the experimental cDNA or empty pcDNA3.1(-) as a control, following the manufacturer's instructions. Each experimental condition was performed in sextuplicate. $48 \mathrm{~h}$ after transfection, the plate was assayed using the Dual-Glo Luciferase Assay System (Promega) and read using a Veritas Microplate Luminometer (Turner Biosystems). Firefly luciferase readings were normalized to Renilla luciferase readings in each well, and the data are represented as fold-change compared to empty pcDNA3.1(-) ( \pm the standard deviation). The following firefly luciferase plasmids were used: the IFNB1-luc construct was a gift from Dr. Jürg Tschopp (University of Lausanne); the Prl promoter AP1-luc construct was from Dr. Ruslan Medzhitov (Yale School of Medicine), and the NF- $\kappa$ B-luc construct was from Dr. Jurgen Brojatsch (Albert Einstein College of Medicine). The MAVS, MYD88, and TAB3 expression constructs are described elsewhere [39].

For single-cycle infectivity assays using the env' luciferase reporter viruses described above, HEK-293 cells or THP-1 macrophages were plated on white, opaque 96-well CulturPlate-96 microplates (PerkinElmer) at $1 \times$ $10^{5}$ cells per well in $100 \mu \mathrm{L}$ tissue culture medium. After $24 \mathrm{~h}$, the cells were challenged with serial dilutions of luciferase reporter viruses. $72 \mathrm{~h}$ after transduction the plate was assayed using the Bright-Glo Luciferase Assay System (Promega) and read using a Veritas Microplate Luminometer (Turner Biosystems). 


\section{IFN- $\beta$ secretion assay}

IFN- $\beta$ secretion was quantified using the reporter cell line HL116, which carries the luciferase gene under the control of the IFN-inducible 6-16 promoter [90] (a kind gift from Dr. Olivier Schwartz, (Institut Pasteur)). HL116 cells, grown in DMEM supplemented with 10\% FBS and hypoxanthine-aminopterin-thymidine (HAT) media supplement, were plated at $2 \times 10^{4}$ cells per well of a 96-well plate, $16 \mathrm{~h}$ prior to the assay. The HL116 cells were then incubated for $7 \mathrm{~h}$ with the culture med-

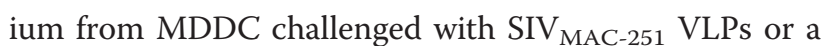
control for $3 \mathrm{~h}$, and then treated with LPS. A titration of recombinant, human IFN- $\beta$ (PBL InterferonSource) was used as a standard. Cells were then lysed with Luciferase Cell Culture Lysis $5 \times$ Reagent (Promega) and luciferase activity was measured using the Luciferase Assay Reagent (Promega), following the manufacturer's instructions.

\section{qPCR for viral CDNA}

qPCR for HIV-1 full-length linear cDNA and 2-LTR circles was performed as described previously [91,92], with the following modifications. The $\mathrm{qPCR}$ reaction was performed in quadruplicate in a $20 \mu \mathrm{L}$ volume using $1 \times$ TaqMan Universal PCR Master Mix (Applied Biosystems), $500 \mathrm{ng}$ of total cellular DNA (isolated from $5 \times$ $10^{6}$ MDDC using the DNeasy Blood \& Tissue Kit (Qiagen)), and $300 \mathrm{nmol} / \mathrm{L}$ forward primer, $300 \mathrm{nmol} / \mathrm{L}$ reverse primer, and $100 \mathrm{nmol} / \mathrm{L}$ probe. Using the 7900 HT Fast Real-Time PCR System (Applied Biosystems), the following program was performed: $50^{\circ} \mathrm{C}$ for $2 \mathrm{~min}$, $95^{\circ} \mathrm{C}$ for $10 \mathrm{~min}$, then 40 cycles of $95^{\circ} \mathrm{C}$ for $15 \mathrm{~s}$ and $60^{\circ}$ $\mathrm{C}$ for $1 \mathrm{~min}$. The following primer and probe sets were used: Late RT: J1 5'-ACAAGCTAGTACCAGTTGAGCCAGATAAG-3', J2 5'- GCCGTGCGCGCTTCAGCAAGC-3', Late RT probe (LRT-P) 5'- (FAM)CAGTGGCGCCCGAACAGGGA-(TAMRA)-3'; 2-LTR circles: 2-LTR forward (MH535): 5'-AACTAGGGAACCCACTGCTTAAG-3', 2-LTR reverse (MH536) 5'-TCCACAGATCAAGGATATCTTGTC-3', 2-LTR probe (MH603) 5'-(FAM)-ACACTACTTGAAGCACTCAAGGCAAGCTTT-(TAMRA) -3'.

Nested Alu-LTR qPCR for HIV-1 provirus was performed as described previously [91,93] with the following modifications. Total DNA was prepared from $5 \times$ $10^{6}$ cells using the DNeasy Blood and Tissue Kit (Qiagen). $500 \mathrm{ng}$ total DNA was diluted in a $50 \mu \mathrm{L}$ reaction with $1 \times$ AccuPrime PCR Buffer II (Invitrogen), $0.2 \mu \mathrm{L}$ AccuPrime High Fidelity Taq polymerase (Invitrogen), and $400 \mathrm{nmol} / \mathrm{L}$ of each primer (Alu forward (MH535) 5'-AACTAGGGAACCCACTGCTTAAG-3' and Alu reverse (SB704) 5'-TGCTGGGATTACAGGCGTGAG$\left.3^{\prime}\right)$. After 2 min denaturing at $94^{\circ} \mathrm{C}, 25$ cycles of $94^{\circ} \mathrm{C}$ for $15 \mathrm{~s}, 55^{\circ} \mathrm{C}$ for $30 \mathrm{~s}$, and $68^{\circ} \mathrm{C}$ for $3 \mathrm{~min}$ were performed, followed by a $10 \mathrm{~min}$ extension at $68^{\circ} \mathrm{C}$. The second round of amplification using a nested primer/ probe set was performed in quadruplicate in a $20 \mu \mathrm{L}$ volume using $1 \times$ TaqMan Universal PCR Master Mix (Applied Biosystems), $2 \mu \mathrm{L}$ of the first round PCR as template, $300 \mathrm{nmol} / \mathrm{L}$ of each forward and reverse primer, and $100 \mathrm{nmol} / \mathrm{L}$ probe on the $7900 \mathrm{HT}$ Fast RealTime PCR System (Applied Biosystems) using the standard mode program with the following changes: $50^{\circ} \mathrm{C}$ for $2 \mathrm{~min}, 95^{\circ} \mathrm{C}$ for $10 \mathrm{~min}$, and 50 cycles of $95^{\circ} \mathrm{C}$ for 15 $\mathrm{s}$ and $60^{\circ} \mathrm{C}$ for $90 \mathrm{~s}$. The following primer/probe combinations were used: Alu II forward 5'-GGTAACTAGAGATCCCTCAGACCCT-3', Alu II reverse 5'GCGTGAGCCACCGC-3', Alu II probe 5'-(FAM)TTAGTCAGTGTGGAAAATCTCTAGCAGGCCG(TAMRA)-3'.

Mitochondrial DNA was used as an internal control with the following primer/probe set: Mito forward (MH533) 5'-ACCCACTCCCTCTTAGCCAATATT-3', Mito reverse (MH534) 5'-GTAGGGCTAGGCCCACCG3', Mito probe 5'-(TET)-CTAGTCTTTGCCGCCTGCGAAGCA-(TAMRA)-3' [91].

\section{Additional material}

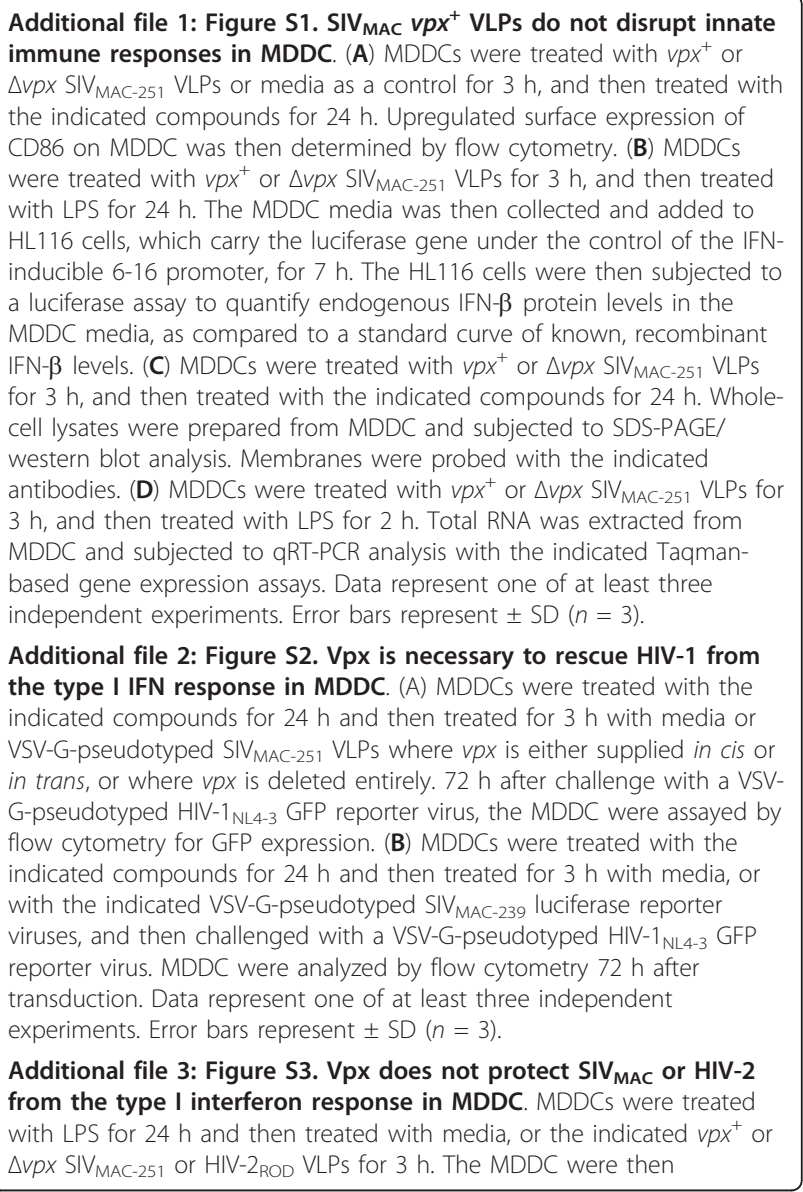

Additional file 1: Figure S1. SIV $_{\mathrm{MAC}} v p x^{+}$VLPs do not disrupt innate immune responses in MDDC. (A) MDDCs were treated with $v p x^{+}$or $\triangle v p x$ SIV $_{\text {MAC-251 }}$ VLPS or media as a control for $3 \mathrm{~h}$, and then treated with the indicated compounds for $24 \mathrm{~h}$. Upregulated surface expression of C86 on MDDC was then determined by flow cytometry. (B) MDDCs with LPS for $24 \mathrm{~h}$. The MDDC media was then collected and added to HL116 cells, which carry the luciferase gene under the control of the IFNinducible 6-16 promoter, for $7 \mathrm{~h}$. The HL116 cells were then subjected to a luciferase assay to quantify endogenous IFN- $\beta$ protein levels in the MDDC media, as compared to a standard curve of known, recombinant IFN- $\beta$ levels. (C) MDDCs were treated with $v p x^{+}$or $\triangle v p x$ SIV MAC-251 VLPS for $3 \mathrm{~h}$, and then treated with the indicated compounds for $24 \mathrm{~h}$. Wholecell lysates were prepared from MDDC and subjected to SDS-PAGE/ western blot analysis. Membranes were probed with the indicated $3 \mathrm{~h}$, and then treated with LPS for $2 \mathrm{~h}$. Total RNA was extracted from MDDC and subjected to qRT-PCR analysis with the indicated Taqmanbased gene expression assays. Data represent one of at least three independent experiments. Error bars represent \pm SD $(n=3)$.

Additional file 2: Figure S2. Vpx is necessary to rescue HIV-1 from the type I IFN response in MDDC. (A) MDDCs were treated with the VSV-G-pseudotyped SIV MAC-251 VLPS where vpx is either supplied in cis or in trans, or where $v p x$ is deleted entirely. $72 \mathrm{~h}$ after challenge with a VSV-

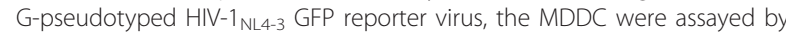
flow cytometry for GFP expression. (B) MDDCs were treated with the indicated compounds for $24 \mathrm{~h}$ and then treated for $3 \mathrm{~h}$ with media, or with the indicated VSV-G-pseudotyped SIV MAC-239 luciferase reporter viruses, and then challenged with a VSV-G-pseudotyped HIV-1 NL4-3 GFP reporter virus. MDDC were analyzed by flow cytometry $72 \mathrm{~h}$ after experiments. Error bars represent \pm SD $(n=3)$. $\triangle v p \times$ SIV $_{\text {MAC-251 }}$ or HIV-2 ROD VLPs for $3 \mathrm{~h}$. The MDDC were then 
challenged with either a SIV MAC-251 (A) or HIV-2ROD (B) GFP reporter vector. MDDCs were analyzed by flow cytometry $72 \mathrm{~h}$ after transduction. Data represent one of at least three independent experiments. Error bars represent \pm SD $(n=3)$.

\section{Additional file 4: Figure $S 4$. Vpx does not disrupt innate immune} signaling. HEK-293 cells were transfected with codon-optimzed SIV MAC251 vpx or empty pcDNA3.1 plasmid as a control, along with a luciferase reporter plasmid for IFNB1 (A), NF- $\kappa$ B (B), or AP-1 (C), and an expression plasmid for MAVS (A), MyD88 (B), or TAB3 (C). Cells were harvested for luciferase assay $48 \mathrm{~h}$ post-transfection. Data are normalized to a Renilla luciferase internal control and are representative of one of at least three independent experiments. Error bars represent \pm SD $(n=6)$.

Additional file 5: Table S1. Codon-optimized nucleic acid sequences Additional file 6: Table S2. Oligonucleotides used for cloning in this study.

\section{Acknowledgements and Funding}

We would like to thank Andrea Cimarelli, Olivier Schwartz, Jacek Skowronski, and Dr. Klaus Strebel for reagents, advice, and discussions. This work was supported by NIH grant RO1Al59159 and Swiss National Science Foundation grant 3100A0-128655 to J.L. The funders had no role in study design; in the collection, analysis, and interpretation of data; in the writing of the manuscript; or in the decision to submit the manuscript for publication.

\section{Authors' contributions}

$T P, C R$, and $J L$ conceived and designed the experiments, analyzed the data, and wrote the paper. TP and CR performed the experiments. All authors read and approved the final manuscript.

\section{Competing interests}

The authors declare that they have no competing interests.

Received: 13 May 2011 Accepted: 22 June 2011 Published: 22 June 2011

\section{References}

1. Malim MH, Emerman M: HIV-1 accessory proteins-ensuring viral survival in a hostile environment. Cell Host Microbe 2008, 3:388-398.

2. Tristem M, Marshall C, Karpas A, Hill F: Evolution of the primate lentiviruses: evidence from vpx and vpr. EMBO J 1992, 11:3405-3412.

3. Sharp PM, Bailes E, Stevenson M, Emerman M, Hahn BH: Gene acquisition in HIV and SIV. Nature 1996, 383:586-587.

4. Gibbs JS, Lackner AA, Lang SM, Simon MA, Sehgal PK, Daniel MD, Desrosiers RC: Progression to AIDS in the absence of a gene for vpr or vpx. J Virol 1995, 69:2378-2383.

5. Hirsch VM, Sharkey ME, Brown CR, Brichacek B, Goldstein S, Wakefield J, Byrum R, Elkins WR, Hahn BH, Lifson JD, Stevenson M: Vpx is required for dissemination and pathogenesis of SIV(SM) PBj: evidence of macrophage-dependent viral amplification. Nat Med 1998, 4:1401-1408.

6. Yu XF, Yu QC, Essex M, Lee TH: The vpx gene of simian immunodeficiency virus facilitates efficient viral replication in fresh lymphocytes and macrophage. J Virol 1991, 65:5088-5091.

7. Balliet JW, Kolson DL, Eiger G, Kim FM, McGann KA, Srinivasan A, Collman R: Distinct effects in primary macrophages and lymphocytes of the human immunodeficiency virus type 1 accessory genes vpr, vpu, and nef: mutational analysis of a primary HIV-1 isolate. Virology 1994, 200:623-631.

8. Gibbs JS, Regier DA, Desrosiers RC: Construction and in vitro properties of SIVmac mutants with deletions in "nonessential" genes. AIDS Res Hum Retroviruses 1994, 10:607-616.

9. Kawamura M, Sakai H, Adachi A: Human immunodeficiency virus Vpx is required for the early phase of replication in peripheral blood mononuclear cells. Microbiol Immunol 1994, 38:871-878.

10. Goujon C, Riviere L, Jarrosson-Wuilleme L, Bernaud J, Rigal D, Darlix JL, Cimarelli A: SIVSM/HIV-2 Vpx proteins promote retroviral escape from a proteasome-dependent restriction pathway present in human dendritic cells. Retrovirology 2007, 4:2.

11. Goujon C, Arfi V, Pertel T, Luban J, Lienard J, Rigal D, Darlix JL, Cimarelli A: Characterization of simian immunodeficiency virus SIVSM/human immunodeficiency virus type $2 \mathrm{Vpx}$ function in human myeloid cells. $J$ Virol 2008, 82:12335-12345.

12. Sharova N, Wu Y, Zhu X, Stranska R, Kaushik R, Sharkey M, Stevenson M: Primate lentiviral Vpx commandeers DDB1 to counteract a macrophage restriction. PLoS Pathog 2008, 4:e1000057.

13. Srivastava S, Swanson SK, Manel N, Florens L, Washburn MP, Skowronski J: Lentiviral Vpx accessory factor targets VprBP/DCAF1 substrate adaptor for cullin 4 E3 ubiquitin ligase to enable macrophage infection. PLOS Pathog 2008, 4:e1000059.

14. Fujita M, Otsuka M, Miyoshi M, Khamsri B, Nomaguchi M, Adachi $A: V p x$ is critical for reverse transcription of the human immunodeficiency virus type 2 genome in macrophages. J Virol 2008, 82:7752-7756.

15. Bergamaschi A, Ayinde D, David A, Le Rouzic E, Morel M, Collin G, Descamps D, Damond F, Brun-Vezinet F, Nisole S, et al: The HIV-2 Vpx protein usurps the CUL4A-DDB1DCAF1 ubiquitin ligase to overcome a post-entry block in macrophage infection. J Virol 2009.

16. Hu J, Gardner MB, Miller CJ: Simian immunodeficiency virus rapidly penetrates the cervicovaginal mucosa after intravaginal inoculation and infects intraepithelial dendritic cells. Journal of virology 2000, 74:6087-6095.

17. Sewell AK, Price DA: Dendritic cells and transmission of HIV-1. Trends in immunology 2001, 22:173-175.

18. Haase AT: Targeting early infection to prevent HIV-1 mucosal transmission. Nature 2010, 464:217-223.

19. Accola MA, Bukovsky AA, Jones MS, Gottlinger HG: A conserved dileucinecontaining motif in p6(gag) governs the particle association of $V p x$ and Vpr of simian immunodeficiency viruses SIV(mac) and SIV(agm). J Virol 1999, 73:9992-9999.

20. Paxton W, Connor Rl, Landau NR: Incorporation of Vpr into human immunodeficiency virus type 1 virions: requirement for the $\mathrm{p} 6$ region of gag and mutational analysis. J Virol 1993, 67:7229-7237.

21. Wu X, Conway JA, Kim J, Kappes JC: Localization of the Vpx packaging signal within the $C$ terminus of the human immunodeficiency virus type 2 Gag precursor protein. J Virol 1994, 68:6161-6169.

22. Jenkins Y, Pornillos O, Rich RL, Myszka DG, Sundquist WI, Malim MH: Biochemical analyses of the interactions between human immunodeficiency virus type $1 \mathrm{Vpr}$ and p6(Gag). Journal of virology 2001, 75:10537-10542.

23. Belshan M, Mahnke LA, Ratner L: Conserved amino acids of the human immunodeficiency virus type 2 Vpx nuclear localization signal are critical for nuclear targeting of the viral preintegration complex in non-dividing cells. Virology 2006, 346:118-126.

24. Di Marzio P, Choe S, Ebright M, Knoblauch R, Landau NR: Mutational analysis of cell cycle arrest, nuclear localization and virion packaging of human immunodeficiency virus type 1 Vpr. J Virol 1995, 69:7909-7916.

25. Heinzinger NK, Bukinsky Ml, Haggerty SA, Ragland AM, Kewalramani V, Lee MA, Gendelman HE, Ratner L, Stevenson M, Emerman M: The Vpr protein of human immunodeficiency virus type 1 influences nuclear localization of viral nucleic acids in nondividing host cells. Proc Natl Acad Sci USA 1994, 91:7311-7315.

26. Fletcher TM, Brichacek B, Sharova N, Newman MA, Stivahtis G, Sharp PM, Emerman M, Hahn BH, Stevenson M: Nuclear import and cell cycle arrest functions of the HIV-1 Vpr protein are encoded by two separate genes in HIV-2/SIV(SM). EMBO J 1996, 15:6155-6165.

27. Freed EO, Englund G, Martin MA: Role of the basic domain of human immunodeficiency virus type 1 matrix in macrophage infection. Journal of virology 1995, 69:3949-3954.

28. Yamashita M, Emerman M: The cell cycle independence of HIV infections is not determined by known karyophilic viral elements. PLoS pathogens 2005, 1:e18.

29. Goujon C, Jarrosson-Wuilleme L, Bernaud J, Rigal D, Darlix JL, Cimarelli A: With a little help from a friend: increasing HIV transduction of monocyte-derived dendritic cells with virion-like particles of SIV(MAC). Gene Ther 2006, 13:991-994.

30. Marin M, Rose KM, Kozak SL, Kabat D: HIV-1 Vif protein binds the editing enzyme APOBEC3G and induces its degradation. Nat Med 2003, 9:1398-1403.

31. Sheehy AM, Gaddis NC, Malim MH: The antiretroviral enzyme APOBEC3G is degraded by the proteasome in response to HIV-1 Vif. Nat Med 2003, 9:1404-1407. 
32. Yu X, Yu Y, Liu B, Luo K, Kong W, Mao P, Yu XF: Induction of APOBEC3G ubiquitination and degradation by an HIV-1 Vif-Cul5-SCF complex. Science 2003, 302:1056-1060.

33. Belzile JP, Duisit G, Rougeau N, Mercier J, Finzi A, Cohen EA: HIV-1 Vprmediated G2 arrest involves the DDB1-CUL4AVPRBP E3 ubiquitin ligase. PLoS Pathog 2007, 3:e85.

34. Hrecka K, Gierszewska M, Srivastava S, Kozaczkiewicz L, Swanson SK, Florens L, Washburn MP, Skowronski J: Lentiviral Vpr usurps Cul4-DDB1 [VprBP] E3 ubiquitin ligase to modulate cell cycle. Proc Natl Acad Sci USA 2007, 104:11778-11783.

35. Le Rouzic E, Belaidouni N, Estrabaud E, Morel M, Rain JC, Transy C, Margottin-Goguet F: HIV1 Vpr arrests the cell cycle by recruiting DCAF1/ VprBP, a receptor of the Cul4-DDB1 ubiquitin ligase. Cell Cycle 2007, 6:182-188.

36. Schrofelbauer B, Hakata Y, Landau NR: HIV-1 Vpr function is mediated by interaction with the damage-specific DNA-binding protein DDB1. Proc Natl Acad Sci USA 2007, 104:4130-4135.

37. Tan L, Ehrlich E, Yu XF: DDB1 and Cul4A are required for human immunodeficiency virus type 1 Vpr-induced G2 arrest. J Virol 2007, 81:10822-10830.

38. Luban J: Cyclophilin A, TRIM5, and resistance to human immunodeficiency virus type 1 infection. J Virol 2007, 81:1054-1061.

39. Pertel T, Hausmann S, Morger D, Züger S, Guerra J, Lascano J, Reinhard C, Santoni F, Uchil PD, Chatel L, et al: TRIM5 is an innate immune sensor for the retrovirus capsid lattice. Nature 2011, 472:361-365.

40. Kornbluth RS, Oh PS, Munis JR, Cleveland PH, Richman DD: Interferons and bacterial lipopolysaccharide protect macrophages from productive infection by human immunodeficiency virus in vitro. J Exp Med 1989, 169:1137-1151.

41. Panne D, Maniatis T, Harrison SC: An atomic model of the interferon-beta enhanceosome. Cell 2007, 129:1111-1123.

42. Medzhitov R: Recognition of microorganisms and activation of the immune response. Nature 2007, 449:819-826.

43. Pancio HA, Ratner L: Human immunodeficiency virus type 2 Vpx-Gag interaction. J Virol 1998, 72:5271-5275.

44. Selig L, Pages JC, Tanchou V, Preveral S, Berlioz-Torrent C, Liu LX, Erdtmann L, Darlix J, Benarous R, Benichou S: Interaction with the p6 domain of the gag precursor mediates incorporation into virions of $\mathrm{Vpr}$ and Vpx proteins from primate lentiviruses. J Virol 1999, 73:592-600.

45. Connor Rl, Chen BK, Choe S, Landau NR: Vpr is required for efficient replication of human immunodeficiency virus type-1 in mononuclear phagocytes. Virology 1995, 206:935-944.

46. Kaul A, Stauffer S, Berger C, Pertel T, Schmitt J, Kallis S, Zayas M, Lohmann V, Luban J, Bartenschlager R: Essential role of cyclophilin A for hepatitis $C$ virus replication and virus production and possible link to polyprotein cleavage kinetics. PLoS Pathog 2009, 5:e1000546.

47. Tsuchiya S, Yamabe M, Yamaguchi Y, Kobayashi Y, Konno T, Tada K: Establishment and characterization of a human acute monocytic leukemia cell line (THP-1). International journal of cancer 1980, 26:171-176.

48. Meylan E, Curran J, Hofmann K, Moradpour D, Binder M, Bartenschlager R, Tschopp J: Cardif is an adaptor protein in the RIG-I antiviral pathway and is targeted by hepatitis C virus. Nature 2005, 437:1167-1172.

49. Li K, Foy E, Ferreon JC, Nakamura M, Ferreon AC, Ikeda M, Ray SC, Gale M $\mathrm{Jr}$, Lemon SM: Immune evasion by hepatitis C virus NS3/4A proteasemediated cleavage of the Toll-like receptor 3 adaptor protein TRIF. Proc Natl Acad Sci USA 2005, 102:2992-2997.

50. Lin R, Lacoste J, Nakhaei P, Sun Q, Yang L, Paz S, Wilkinson P, Julkunen I, Vitour D, Meurs E, Hiscott J: Dissociation of a MAVS/IPS-1/VISA/CardifIKKepsilon molecular complex from the mitochondrial outer membrane by hepatitis C virus NS3-4A proteolytic cleavage. J Virol 2006, 80:6072-6083.

51. Loo YM, Owen DM, Li K, Erickson AK, Johnson CL, Fish PM, Carney DS, Wang $\mathrm{T}$, Ishida $\mathrm{H}$, Yoneyama $\mathrm{M}$, et al: Viral and therapeutic control of IFNbeta promoter stimulator 1 during hepatitis $C$ virus infection. Proc Natl Acad Sci USA 2006, 103:6001-6006.

52. Drahos J, Racaniello VR: Cleavage of IPS-1 in cells infected with human rhinovirus. Journal of virology 2009, 83:11581-11587.

53. Barral PM, Sarkar D, Fisher PB, Racaniello VR: RIG-I is cleaved during picornavirus infection. Virology 2009, 391:171-176.

54. Mangeat B, Gers-Huber G, Lehmann M, Zufferey M, Luban J, Piguet V: HIV-1 Vpu neutralizes the antiviral factor Tetherin/BST-2 by binding it and directing its beta-TrCP2-dependent degradation. PLoS pathogens 2009, 5: e1000574.

55. Mitchell RS, Katsura C, Skasko MA, Fitzpatrick K, Lau D, Ruiz A, Stephens EB, Margottin-Goguet F, Benarous R, Guatelli JC: Vpu antagonizes BST-2mediated restriction of HIV-1 release via beta-TrCP and endo-lysosomal trafficking. PLoS pathogens 2009, 5:e1000450.

56. Douglas JL, Viswanathan K, McCarroll MN, Gustin JK, Fruh K, Moses AV: Vpu directs the degradation of the human immunodeficiency virus restriction factor BST-2/Tetherin via a beta\}TrCP-dependent mechanism. Journal of virology 2009, 83:7931-7947.

57. Goila-Gaur R, Strebel K: HIV-1 Vif, APOBEC, and intrinsic immunity. Retrovirology 2008, 5:51

58. Perez-Caballero D, Zang T, Ebrahimi A, McNatt MW, Gregory DA, Johnson MC, Bieniasz PD: Tetherin inhibits HIV-1 release by directly tethering virions to cells. Cell 2009, 139:499-511.

59. Sheehy AM, Gaddis NC, Choi JD, Malim MH: Isolation of a human gene that inhibits HIV-1 infection and is suppressed by the viral Vif protein. Nature 2002, 418:646-650.

60. Neil SJ, Zang T, Bieniasz PD: Tetherin inhibits retrovirus release and is antagonized by HIV-1 Vpu. Nature 2008, 451:425-430.

61. Van Damme N, Goff D, Katsura C, Jorgenson RL, Mitchell R, Johnson MC Stephens EB, Guatelli J: The interferon-induced protein BST-2 restricts HIV-1 release and is downregulated from the cell surface by the viral Vpu protein. Cell Host Microbe 2008, 3:245-252.

62. McNab FW, Rajsbaum R, Stoye JP, O'Garra A: Tripartite-motif proteins and innate immune regulation. Current opinion in immunology 2011, 23:46-56.

63. Uchil PD, Quinlan BD, Chan WT, Luna JM, Mothes W: TRIM E3 ligases interfere with early and late stages of the retroviral life cycle. PLOS Pathog 2008, 4:e16.

64. Kajaste-Rudnitski A, Marelli SS, Pultrone C, Pertel T, Uchil PD, Mechti N, Mothes W, Poli G, Luban J, Vicenzi E: TRIM22 Inhibits HIV-1 Transcription Independently of Its E3-Ubiquitin Ligase Activity, Tat and NF-\{kappa\}B Responsive LTR Elements. Journal of virology 2011.

65. Bogerd HP, Wiegand HL, Hulme AE, Garcia-Perez JL, O'Shea KS, Moran JV, Cullen BR: Cellular inhibitors of long interspersed element 1 and Alu retrotransposition. Proc Natl Acad Sci USA 2006, 103:8780-8785.

66. Chen H, Lilley CE, Yu Q, Lee DV, Chou J, Narvaiza I, Landau NR, Weitzman MD: APOBEC3A is a potent inhibitor of adeno-associated virus and retrotransposons. Curr Biol 2006, 16:480-485.

67. Berger A, Munk C, Schweizer M, Cichutek K, Schule S, Flory E: Interaction of Vpx and apolipoprotein B mRNA-editing catalytic polypeptide 3 family member A (APOBEC3A) correlates with efficient lentivirus infection of monocytes. The Journal of biological chemistry 2010, 285:12248-12254.

68. Peng G, Greenwell-Wild T, Nares S, Jin W, Lei KJ, Rangel ZG, Munson PJ, Wahl SM: Myeloid differentiation and susceptibility to HIV-1 are linked to APOBEC3 expression. Blood 2007, 110:393-400.

69. Hrecka K, Haol C, Gierszewska M, Swanson SK, Kesik-Brodacka M, Srivastava S, Florens L, Washburn MP, Skowronski J: Vpx relieves inhibition of HIV-1 infection of macrophages mediated by the SAMHD1 protein. Nature 2011.

70. Laguette N, Sobhian B, Casartelli N, Ringeard M, Chable-Bessia C, Segeral E, Yatim A, Emiliani S, Schwartz O, Benkirane M: SAMHD1 is the dendriticand myeloid-cell-specific HIV-1 restriction factor counteracted by Vpx. Nature 2011.

71. DeHart JL, Zimmerman ES, Ardon O, Monteiro-Filho CM, Arganaraz ER, Planelles V: HIV-1 Vpr activates the G2 checkpoint through manipulation of the ubiquitin proteasome system. Virol J 2007, 4:57.

72. Wen $X$, Duus KM, Friedrich TD, de Noronha CM: The HIV1 protein Vpr acts to promote $\mathrm{G} 2$ cell cycle arrest by engaging a DDB1 and Cullin4Acontaining ubiquitin ligase complex using VprBP/DCAF1 as an adaptor. $J$ Biol Chem 2007, 282:27046-27057.

73. Yamashita M, Emerman M: Retroviral infection of non-dividing cells: old and new perspectives. Virology 2006, 344:88-93.

74. Yamashita M, Perez O, Hope TJ, Emerman M: Evidence for direct involvement of the capsid protein in HIV infection of nondividing cells. PLoS pathogens 2007, 3:1502-1510.

75. Manel N, Hogstad B, Wang Y, Levy DE, Unutmaz D, Littman DR: A cryptic sensor for HIV-1 activates antiviral innate immunity in dendritic cells. Nature 2010, 467:214-217.

76. Banchereau J, Steinman RM: Dendritic cells and the control of immunity. Nature 1998, 392:245-252. 
77. Steinman RM, Banchereau J: Taking dendritic cells into medicine. Nature 2007, 449:419-426

78. Medzhitov R, Littman D: HIV immunology needs a new direction. Nature 2008, 455:591.

79. Negre D, Mangeot PE, Duisit G, Blanchard S, Vidalain PO, Leissner P, Winter AJ, Rabourdin-Combe C, Mehtali M, Moullier P, et al: Characterization of novel safe lentiviral vectors derived from simian immunodeficiency virus (SIVmac251) that efficiently transduce mature human dendritic cells. Gene Ther 2000, 7:1613-1623.

80. Papkalla A, Munch J, Otto C, Kirchhoff F: Nef enhances human immunodeficiency virus type 1 infectivity and replication independently of viral coreceptor tropism. J Virol 2002, 76:8455-8459.

81. Schindler M, Munch J, Kutsch O, Li H, Santiago ML, Bibollet-Ruche F, MullerTrutwin MC, Novembre FJ, Peeters M, Courgnaud V, et al: Nef-mediated suppression of $\mathrm{T}$ cell activation was lost in a lentiviral lineage that gave rise to HIV-1. Cell 2006, 125:1055-1067.

82. He J, Chen Y, Farzan M, Choe H, Ohagen A, Gartner S, Busciglio J, Yang X, Hofmann W, Newman W, et al: CCR3 and CCR5 are co-receptors for HIV-1 infection of microglia. Nature 1997, 385:645-649.

83. Chen BK, Saksela K, Andino R, Baltimore D: Distinct modes of human immunodeficiency virus type 1 proviral latency revealed by superinfection of nonproductively infected cell lines with recombinant luciferase-encoding viruses. J Virol 1994, 68:654-660.

84. Berthoux L, Sebastian S, Sokolskaja E, Luban J: Lv1 inhibition of human immunodeficiency virus type 1 is counteracted by factors that stimulate synthesis or nuclear translocation of viral cDNA. J Virol 2004, 78:11739-11750.

85. Zhang YJ, Hatziioannou T, Zang T, Braaten D, Luban J, Goff SP, Bieniasz PD: Envelope-dependent, cyclophilin-independent effects of glycosaminoglycans on human immunodeficiency virus type 1 attachment and infection. J Virol 2002, 76:6332-6343.

86. Mangeot PE, Duperrier K, Negre D, Boson B, Rigal D, Cosset FL, Darlix JL: High levels of transduction of human dendritic cells with optimized SIV vectors. Mol Ther 2002, 5:283-290.

87. Pizzato M, Erlwein O, Bonsall D, Kaye S, Muir D, McClure MO: A one-step SYBR Green I-based product-enhanced reverse transcriptase assay for the quantitation of retroviruses in cell culture supernatants. J Virol Methods 2009, 156:1-7.

88. Simm M, Shahabuddin M, Chao W, Allan JS, Volsky DJ: Aberrant Gag protein composition of a human immunodeficiency virus type 1 vif mutant produced in primary lymphocytes. J Virol 1995, 69:4582-4586.

89. Kappes JC, Parkin JS, Conway JA, Kim J, Brouillette CG, Shaw GM, Hahn BH: Intracellular transport and virion incorporation of vpx requires interaction with other virus type-specific components. Virology 1993, 193:222-233.

90. Uze G, Di Marco S, Mouchel-Vielh E, Monneron D, Bandu MT, Horisberger MA, Dorques A, Lutfalla G, Mogensen KE: Domains of interaction between alpha interferon and its receptor components. $J \mathrm{Mol}$ Biol 1994, 243:245-257.

91. Butler SL, Hansen MS, Bushman FD: A quantitative assay for HIV DNA integration in vivo. Nat Med 2001, 7:631-634.

92. Braaten D, Franke EK, Luban J: Cyclophilin A is required for an early step in the life cycle of human immunodeficiency virus type 1 before the initiation of reverse transcription. J Virol 1996, 70:3551-3560.

93. Zhang J, Scadden DT, Crumpacker CS: Primitive hematopoietic cells resist HIV-1 infection via p21. J Clin Invest 2007, 117:473-481.

doi:10.1186/1742-4690-8-49

Cite this article as: Pertel et al:: Vpx rescues HIV-1 transduction of dendritic cells from the antiviral state established by type 1 interferon. Retrovirology 2011 8:49.

\section{Submit your next manuscript to BioMed Central and take full advantage of:}

- Convenient online submission

- Thorough peer review

- No space constraints or color figure charges

- Immediate publication on acceptance

- Inclusion in PubMed, CAS, Scopus and Google Scholar

- Research which is freely available for redistribution

Submit your manuscript at www.biomedcentral.com/submit
Biomed Central 